\title{
Article \\ A Novel Synthesis of ZnO Nanoflower Arrays Using a Lift-Off Technique with Different Thicknesses of Al Sacrificial Layers on a Patterned Sapphire Substrate
}

\author{
Hsien-Wei Tseng ${ }^{1}$, Ching-Shan Wang ${ }^{2}$, Fang-Hsing Wang ${ }^{2, *}$, Han-Wen Liu ${ }^{2}$ and Cheng-Fu Yang ${ }^{3,4, *}$ \\ 1 College of Artificial Intelligence, Yango University, Mawei District, Fuzhou 350015, China; \\ hsienwei.tseng@gmail.com \\ 2 Graduate Institute of Optoelectronic Engineering, National Chung Hsing University, \\ Taichung 402, Taiwan; ching.shan73@msa.hinet.net (C.-S.W.); hwliu@dragon.nchu.edu.tw (H.-W.L.) \\ 3 Department of Chemical and Materials Engineering, National University of Kaohsiung, \\ Kaohsiung 811, Taiwan \\ 4 Department of Aeronautical Engineering, Chaoyang University of Technology, Taichung 413, Taiwan \\ * Correspondence: fansen@dragon.nchu.edu.tw (F.-H.W.); cfyang@nuk.ecu.tw (C.-F.Y.)
}

check for updates

Citation: Tseng, H.-W.; Wang, C.-S.; Wang, F.-H.; Liu, H.-W.; Yang, C.-F. A Novel Synthesis of ZnO Nanoflower Arrays Using a Lift-Off Technique with Different Thicknesses of $\mathrm{Al}$ Sacrificial Layers on a Patterned Sapphire Substrate. Nanomaterials 2022, 12, 612. https://doi.org/ 10.3390/nano12040612

Academic Editors: Valentin Craciun, Felicia Iacomi and Romulus Tetean

Received: 15 January 2022

Accepted: 8 February 2022

Published: 11 February 2022

Publisher's Note: MDPI stays neutral with regard to jurisdictional claims in published maps and institutional affiliations.

Copyright: (c) 2022 by the authors. Licensee MDPI, Basel, Switzerland. This article is an open access article distributed under the terms and conditions of the Creative Commons Attribution (CC BY) license (https:// creativecommons.org/licenses/by/ $4.0 /)$.

\begin{abstract}
A novel method to synthesize large-scale $\mathrm{ZnO}$ nanoflower arrays using a protrusion patterned $\mathrm{ZnO}$ seed layer was investigated. Different thicknesses of aluminum (Al) film were deposited on the concave patterned sapphire substrate as a sacrificial layer. $\mathrm{ZnO}$ gel was layered onto the $\mathrm{Al}$ film as a seed layer and OE-6370HF AB optical glue was used as the adhesive material. A lift-off technique was used to transfer the protrusion patterned $\mathrm{ZnO} / \mathrm{AB}$ glue seed layer to a P-type $\mathrm{Si}<100>$ wafer. The hydrothermal method using $\mathrm{Zn}\left(\mathrm{CH}_{3} \mathrm{COO}\right)_{2}$ and $\mathrm{C}_{6} \mathrm{H}_{12} \mathrm{~N}_{4}$ solutions as liquid precursors was used to synthesize $\mathrm{ZnO}$ nanoflower arrays on the patterned seed layer. X-ray diffraction spectra, field-effect scanning electron microscopy, focused ion beam milling (for obtaining cross-sectional views), and photoluminescence (PL) spectrometry were used to analyze the effects that different synthesis times and different thicknesses of $\mathrm{Al}$ sacrificial layer had on the properties of $\mathrm{ZnO}$ nanoflower arrays. These effects included an increased diameter, and a decreased height, density (i.e., number of nanorods in $\mu \mathrm{m}^{-2}$ ), total surface area, total volume, and maximum emission intensity of PL spectrum. We showed that when the synthesis time and the thickness of the Al sacrificial layer were increased, the emission intensities of the ultraviolet light and visible light had different variations.
\end{abstract}

Keywords: lift-off technique; patterned sapphire substrate; aluminum sacrificial layer; ZnO nanoflower arrays

\section{Introduction}

Zinc oxide $(\mathrm{ZnO})$ is used in a variety of materials with many different applications, including nano- $\mathrm{ZnO} / \mathrm{Ag}$ in antimicrobial applications [1], and Co-doped $\mathrm{ZnO}$ sensors, especially CoZnO-3, exhibited a superior performance in sensing triethylamine (TEA) [2]. $\mathrm{ZnO}$-based materials are versatile because they have many different properties [3], including ultraviolet (UV) and visible light luminescence [4], high electrical conductivity [5], and high piezoelectricity [6]. ZnO can be easily synthesized into nanostructures at low temperatures using a solution process, because this growing process can synthesize the $\mathrm{ZnO}$ nanostructure materials at temperatures lower than $100{ }^{\circ} \mathrm{C}[5,7,8]$. Therefore, this synthesis technology can be easily used to fabricate $\mathrm{ZnO}$-based nanomaterials. These $\mathrm{ZnO}$ nanostructures include thin film, nanoparticles, hollow spheres, nanorods, and nanoflowers, which all have good chemical stability, are nontoxic, and can be synthesized at a low cost. Therefore, ZnO-based nanostructured materials have become one of the most common metal oxide photocatalysts [7,8]. The properties of $\mathrm{ZnO}$-based materials are mainly 
influenced by their fabrication method, structure, and outward appearance, including surface defects and optical bandgap characteristics. Methods to increase the pore structure and, thus, the surface area for optimal dye regeneration and sensitization have been investigated in $\mathrm{ZnO}$-based materials with three-dimensional (3D) structures and morphologies [9]. The surface area of a $\mathrm{ZnO}$-based nanomaterial is an important factor that influences its optical properties.

Nanomaterials with high surface areas have a better ability to absorb scattered light or to emit excited light; thus, the light harvesting efficiency or light emission efficiency of these materials are improved. There is interest in increasing the surface area of $\mathrm{ZnO}$ nanomaterials with one-dimensional (1D) morphologies, such as $\mathrm{ZnO}$ nanorods and $\mathrm{ZnO}$ nanowires, which would be advantageous in terms of light harvesting and emission [10], which can be used to enhance the efficiency of the fabricated devices [11]. There have been many efforts to combine the 3D synthesis model into $1 \mathrm{D} \mathrm{ZnO}$ nanostructures to increase their effective surface areas. For example, researchers have tried to synthesize nanorods that grow vertically from the substrate into randomly branched nanoflower structures. Efforts have been made to optimize the fabrication technology of $\mathrm{ZnO}$ nanoflowers with controllable and repeatable morphologies to form $\mathrm{ZnO}$ nanoflower arrays. For example, $\mathrm{Yu}$ et al. synthesized $\mathrm{ZnO}$ nanoflower arrays on a patterned sapphire substrate with a periodical structure using a two-step method [12]. Guo et al. combined laser direct writing with the hydrothermal method to synthesize $\mathrm{ZnO}$ on polymethyl methacrylate [13]. Kim et al. synthesized double-faced $\mathrm{ZnO}$ nanoflowers by first transferring $\mathrm{ZnO}$-coated microparticles onto a polyimide substrate that had been coated with polyvinyl phenol and then removing the microparticles [14]. Bourfaa et al. arranged different surface positions of the seed layer to control the synthesis of $\mathrm{ZnO}$ nanorods and $\mathrm{ZnO}$ nanoflowers [15].

Although there are many methods that have been used to synthesize $1 \mathrm{D} \mathrm{ZnO}$ nanostructured materials, the hydrothermal method is the most commonly used technology. The hydrothermal method is a simple, useful, and economical way to synthesize 1D ZnO nanostructured materials at low temperatures [16]. ZnO nanoflowers have different outstanding applications in diverse fields beyond themselves. For example, they can be used in water detoxification and environmental remediation [17]. In addition, $\mathrm{ZnO}$ nanoflowers have a detoxification ability against the methylene blue, rhodamine $6 \mathrm{G}$, and oxytetracycline molecules solution in water [18]. Therefore, the hydrothermal method was used in this research to synthesize $\mathrm{ZnO}$ nanoflowers on a prepared protrusion patterned $\mathrm{ZnO}$ seed layer. In this study, we investigated the synthesis of $\mathrm{ZnO}$ nanoflower arrays using a lift-off technique with different thicknesses of Al sacrificial layers on a patterned sapphire substrate. A ZnO film/OE-6370HF AB optical glue multilayer film coated with a patterned concave sapphire substrate was moved to a P-type silicon (Si) $<100>$ wafer to form a protrusion patterned $\mathrm{ZnO}$ seed layer. The hydrothermal method was used to synthesize $\mathrm{ZnO}$ nanorods using $0.02 \mathrm{M} \mathrm{C}_{6} \mathrm{H}_{12} \mathrm{~N}_{4}$ (hexamethylenetetramine (HMT)) and $\mathrm{Zn}\left(\mathrm{CH}_{3} \mathrm{COO}\right)_{2}$ (zinc acetate) solutions as precursors. The synthesized $\mathrm{ZnO}$ nanorods grew perpendicular to the protrusions in the $\mathrm{ZnO}$ seed layer in a radial direction, such that they formed a hierarchical structure. Therefore, this method was successfully used to synthesize $\mathrm{ZnO}$ nanoflowers.

The important novel technology presented in this study was that of a protrusion patterned $\mathrm{ZnO}$ seed layer used to fabricate $\mathrm{ZnO}$ nanoflowers that possessed a remarkable repeatability to form $\mathrm{ZnO}$ nanoflower arrays. In the past, Guo et al. used the spinning method to layer PMMA $1 \mu \mathrm{m}$ thick onto a $\mathrm{GaN} / \mathrm{LiAlO}_{2}$ substrate; then they used a laser to write the holes in the matrix. Then they used the hydrothermal method to synthesize the nanoflowers on the prepared substrate [13]. A shortcoming of this research is that they used the expensive $\mathrm{GaN} / \mathrm{LiAlO}_{2}$ substrate and a laser to prepare that substrate. Katiyar et al. used the ultrasonic-assisted hydrothermal method to grow the $\mathrm{ZnO}$ nanoflowers at a low temperature with no substrate [19]. A shortcoming of this research is that they could not synthesize the $\mathrm{ZnO}$ nanoflowers in the array or matrix structure. Huo et al. applied the self-assembled method to a monolayer polystyrene (PS) sphere, and then they 
used the matrix PS spheres to synthesize the $\mathrm{ZnO}$ nanorods with a matrix structure [20]. However, Huo et al. could not synthesize the $\mathrm{ZnO}$ nanorods in the structure of the $\mathrm{ZnO}$ nanoflowers. In order to improve on these shortcomings, we investigated a novel and easy method to synthesize the $\mathrm{ZnO}$ nanoflower arrays. The investigated method has the following advantages. First, the fabrication processes are easy to duplicate; second, the templates can be simply manufactured; third, the processes make it easy to manufacture $\mathrm{ZnO}$ nanoflowers with large areas. At first, a commercially available sapphire with a concave pattern was used as the substrate. After the $\mathrm{ZnO}$ seed layer was spun onto the substrate and annealed, an optical glue was layered onto the $\mathrm{ZnO}$ seed layer as the carrier. Next, a lift-off technology was used to transfer the $\mathrm{ZnO}$ seed layer on the Si wafer and the protrusion patterned $\mathrm{ZnO} / \mathrm{AB}$ glue seed layer with a matrix structure was obtained. The $\mathrm{ZnO} / \mathrm{AB}$ glue seed layer had the protrusion and matrix structure; therefore, we could easily synthesize the $\mathrm{ZnO}$ nanoflower arrays. We also investigated the effects that different synthesis times and thicknesses of Al sacrificial layers had on the physical and optical properties of the $\mathrm{ZnO}$ nanoflower arrays. The following properties of the $\mathrm{ZnO}$ nanoflower arrays were investigated: the diameter (D), height $(\mathrm{H})$, density or number of nanorods per unit area $\left(\mu \mathrm{m}^{-2}\right)$, total surface area per unit area $\left(\mathrm{S}, \mathrm{nm}^{2}\right)$, total volume per unit area $\left(\mathrm{V}, \mathrm{nm}^{3}\right)$, and photoluminescence (PL) spectrum. Changes in the characteristic emissions in the PL spectra of the $\mathrm{ZnO}$ nanoflower arrays under different synthesis times were also investigated.

\section{Materials and Methods}

In this study, a lift-off technique was used to transfer a $\mathrm{ZnO}$ seed layer with periodic arrays and a protrusion patterned structure to a P-type $\mathrm{Si}<100>$ wafer. The hydrothermal method was then used to synthesize $\mathrm{ZnO}$ nanorods on the $\mathrm{ZnO}$ seed layer to construct $\mathrm{ZnO}$ nanoflower arrays. In order to synthesize the $\mathrm{ZnO}$ nanoflower arrays, we used a sapphire substrate as a template, which had a patterned concave structure and was provided by Shun Haw Technology Ltd. (Taichung, Taiwan), to prepare the ZnO seed layer with a patterned convex structure [4]. The cross-sectional and top views of the 2 inch sapphire substrate are shown in Figure $1 \mathrm{a}, \mathrm{b}$. The average bottom width and height of the protruding nano-structures in sapphire were $0.37 \mu \mathrm{m}$ and $0.48 \mu \mathrm{m}$, respectively.
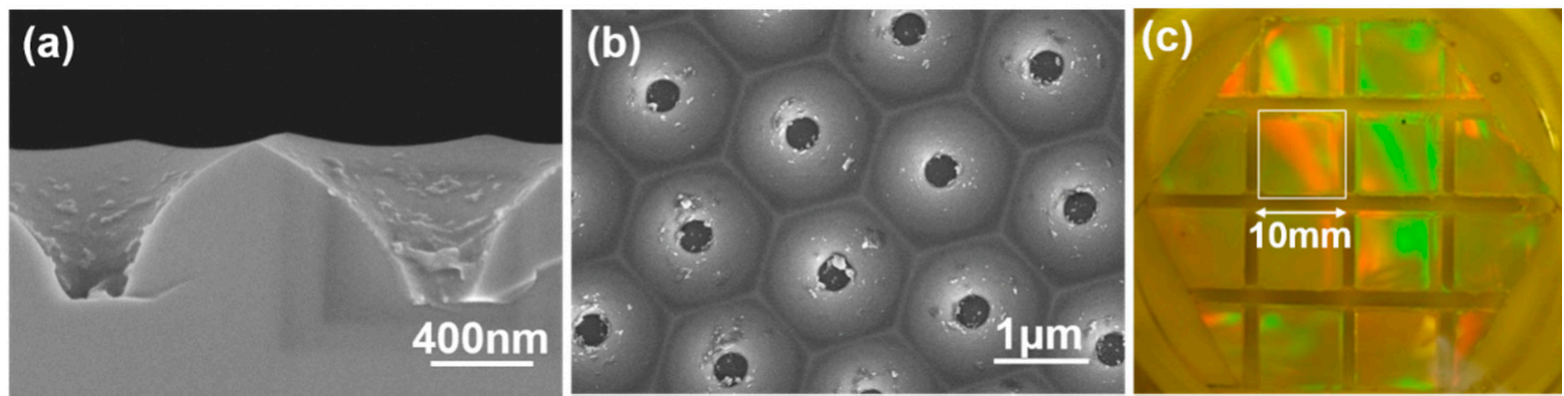

Figure 1. (a) Cross-sectional and (b) top views of the morphologies of a two-inch sapphire substrate. (c) The Al-coated sapphire substrate with heat-resistant tape.

First, a thermal evaporation coating machine (Chuang Pao Special Precision Industry Co. Ltd., Tainan, Taiwan) was used to deposit Al sacrificial layers of different thicknesses on the sapphire substrate [3]. The deposition process was started at a pressure of $2 \times 10^{-6}$ torr and no gas was introduced during the deposition process. Sample A, which was abbreviated as SC-A, had an Al thickness of $120 \mathrm{~nm}$; sample B (SC-B) and sample C (SC-C) had Al thicknesses of 420 and $720 \mathrm{~nm}$, respectively. Heat-resistant tape $\left(260{ }^{\circ} \mathrm{C}\right.$ type, Jaan Yahn Printing Enterprise Co. Ltd., Taichung, Taiwan) was used as an adhesive on the Al-coated sapphire substrate to create an access for sacrificial removal of the Al film from underneath the $\mathrm{ZnO}$ seed layer. The area that was used to prepare the $\mathrm{ZnO}$ seed layer was $10 \mathrm{~mm} \times 10 \mathrm{~mm}$, as shown in Figure 1c. The spin coating method was used to fully 
cover the Al-coated sapphire substrate after the $\mathrm{ZnO}$ gel had been dipped onto the surface. The $\mathrm{ZnO}$-gel-coated template was then baked at $300{ }^{\circ} \mathrm{C}$ for $10 \mathrm{~min}$. The $\mathrm{ZnO}$ gel dipping and baking processes were repeated six times to obtain the appropriate thickness. Optical glue (OE-6370HF AB, Sil-More Industrial Ltd., Hsinchu, Taiwan) was used as the carrier of the $\mathrm{ZnO}$ seed layer. The $\mathrm{Al}$ sacrificial layer was then removed using etching technology; an etching solution of $\mathrm{K}_{3} \mathrm{Fe}(\mathrm{CN})_{6}: \mathrm{KOH}: \mathrm{H}_{2} \mathrm{O}(10 \mathrm{~g}: 1 \mathrm{~g}: 100 \mathrm{~mL})$ was used with an etching speed of the process that varied at $10 \mathrm{~min} / \mathrm{s}$. After the $\mathrm{Al}$ film was etched, the protrusion patterned $\mathrm{ZnO} / \mathrm{AB}$ glue seed layers were obtained; then they were lifted off the sapphire substrate and transferred to the P-type $\mathrm{Si}<100>$ wafer. The OE-6370HF AB glue was used to attach the $\mathrm{ZnO} / \mathrm{AB}$ glue seed layers to the $\mathrm{Si}<100>$ wafer. Finally, the hydrothermal method was used to synthesize the $\mathrm{ZnO}$ nanoflower arrays, because the sapphire substrate had the structure of concave pattern arrays, as Figure 1a,b shows. Therefore, we could use it to prepare a protrusion patterned $\mathrm{ZnO}$ seed layer to synthesize $\mathrm{ZnO}$ nanoflower arrays.

During the synthesis process, the concentrations of $\mathrm{C}_{6} \mathrm{H}_{12} \mathrm{~N}_{4}$ and $\mathrm{Zn}\left(\mathrm{CH}_{3} \mathrm{COO}\right)_{2}$ were maintained at $0.02 \mathrm{M}$, while the duration of the process was increased from $10 \mathrm{~min}$ to $60 \mathrm{~min}$. After the $\mathrm{ZnO}$ nanoflower arrays were synthesized on the protrusion patterned $\mathrm{ZnO}$ seed layer, their $\mathrm{X}$-ray diffraction spectra (XRD, Panalytical, $18 \mathrm{KW}$ rotating anode $\mathrm{X}$-ray generator) were measured to analyze the crystalline phases. Field emission scanning electron microscopy (FESEM, JEOL JSM-6700F, Tokyo, Japan) was used to observe the surface morphologies of the arrays. The prepared protrusion patterned $\mathrm{ZnO}$ seed layer and the $\mathrm{ZnO}$ nanoflower arrays were cut using a focused ion beam (FIB, FEI Helios 1200+, Hillsboro, OR, USA) system so that the cross-sectional morphologies could be observed. FESEM equipped with energy-dispersive X-ray spectroscopy (EDS, Bruker Quantax 200, Billerica, MA, USA) was used to analyze the undefined residual particles on the surface of the prepared protrusion patterned $\mathrm{ZnO}$ seed layer. An iHR550 fluorescence spectrophotometer (Horiba Jobin Yvon, Bensheim, Germany) with a single laser at a wavelength of $325 \mathrm{~nm}$ was used as the excitation light source. The PL properties of the $\mathrm{ZnO}$ nanoflower arrays in the wavelength range of $350 \sim 650 \mathrm{~nm}$ at room temperature were measured.

\section{Results and Discussion}

\subsection{The $\mathrm{ZnO}$ Seed Layer Analysis \\ 3.1.1. XRD Analyses}

The XRD spectra were used to analyze the crystal characteristics of the $\mathrm{ZnO}$ seed layers. The XRD spectra for the SC-A, SC-B, and SC-C substrates are shown in Figure 2. There were there unapparent diffraction peaks in all XRD spectra at about $31.72^{\circ}, 34.40^{\circ}$, and $36.18^{\circ}$, which correspond to the diffraction peaks at the (100), (002), and (101) planes. When the diffraction peaks were compared with the Joint Committee on Powder Diffraction Standards (JCPDS) card number 36-1451, the spectra indicated that the $\mathrm{ZnO}$ seed layers have a wurtzite structure with a hexagonal close-packed (HCP) array. For all the XRD spectra shown in Figure 2, the diffraction peak at the (002) plane did not have the highest diffraction intensity, which suggests that the prepared $\mathrm{ZnO}$ seed layers did not exhibit the preferred orientation along (002) (the c-axis preferred orientation property).

\subsubsection{FE-SEM Analyses}

Figure 3 shows the FESEM surface images of the prepared $\mathrm{ZnO}$ seed layer for $\mathrm{Al}$ sacrificial layers of various thicknesses. These images prove that the lift-off technology successfully transferred the $\mathrm{ZnO}$ seed layer from the sapphire substrate to the P-type $\mathrm{Si}<100>$ wafers to form a protrusion patterned $\mathrm{ZnO}$ seed layer. Figure $3 \mathrm{a}-\mathrm{c}$ shows the low-magnification SEM images of the surface of the prepared $\mathrm{ZnO}$ seed layer on $\mathrm{Al}$ sacrificial layers of different thicknesses. The images show breakages between the different protrusions; in addition, white particles can be seen in the gaps and on the surfaces of the protrusions. One possible reason for these observations is that the substrate was immersed for a long time in the etching solution, which contained $\mathrm{KOH}$. The $\mathrm{KOH}$ reacted with the $\mathrm{Al}$ 
to form white particles of aluminum hydroxide $\left(\mathrm{Al}(\mathrm{OH})_{3}\right)$, which deposited on the surfaces of the protrusions and in the gaps. When EDS was used to analyze the white particles, the $\mathrm{Al}$ element was indeed readily detected.

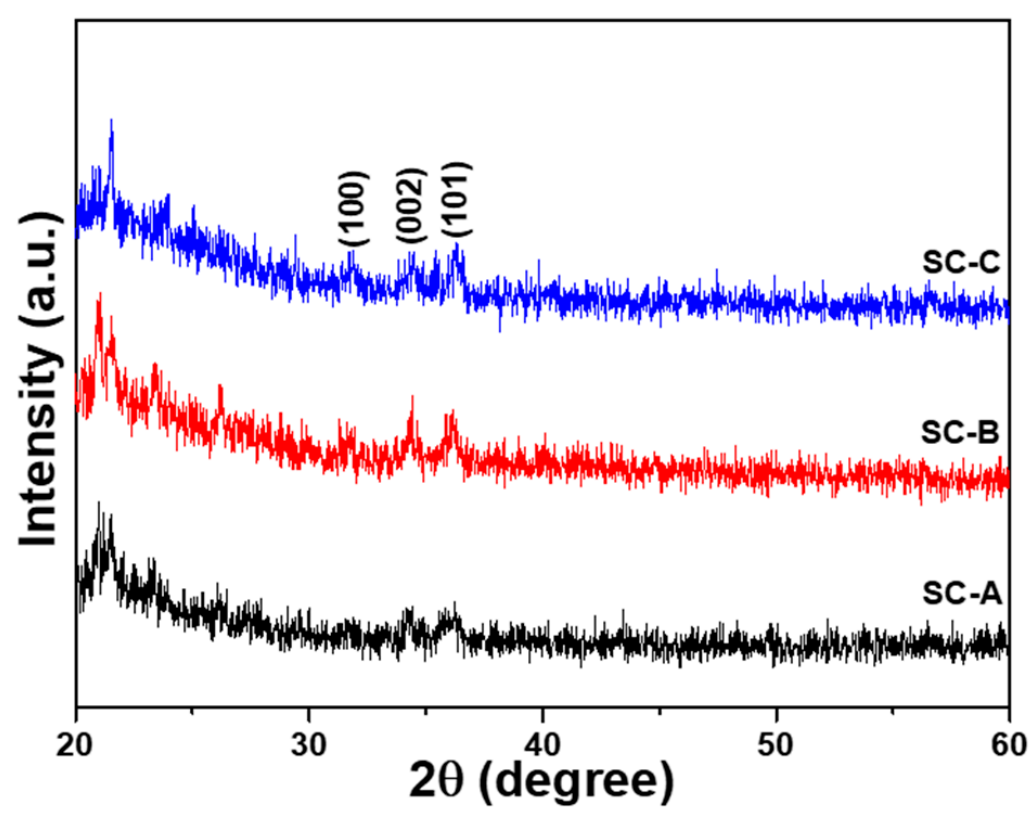

Figure 2. XRD spectra of the $\mathrm{ZnO}$ seed layers on substrates with different thicknesses of $\mathrm{Al}$ sacrificial layers. Al thicknesses for SC-A, SC-B, and SC-C were 120, 420, and $720 \mathrm{~nm}$, respectively.
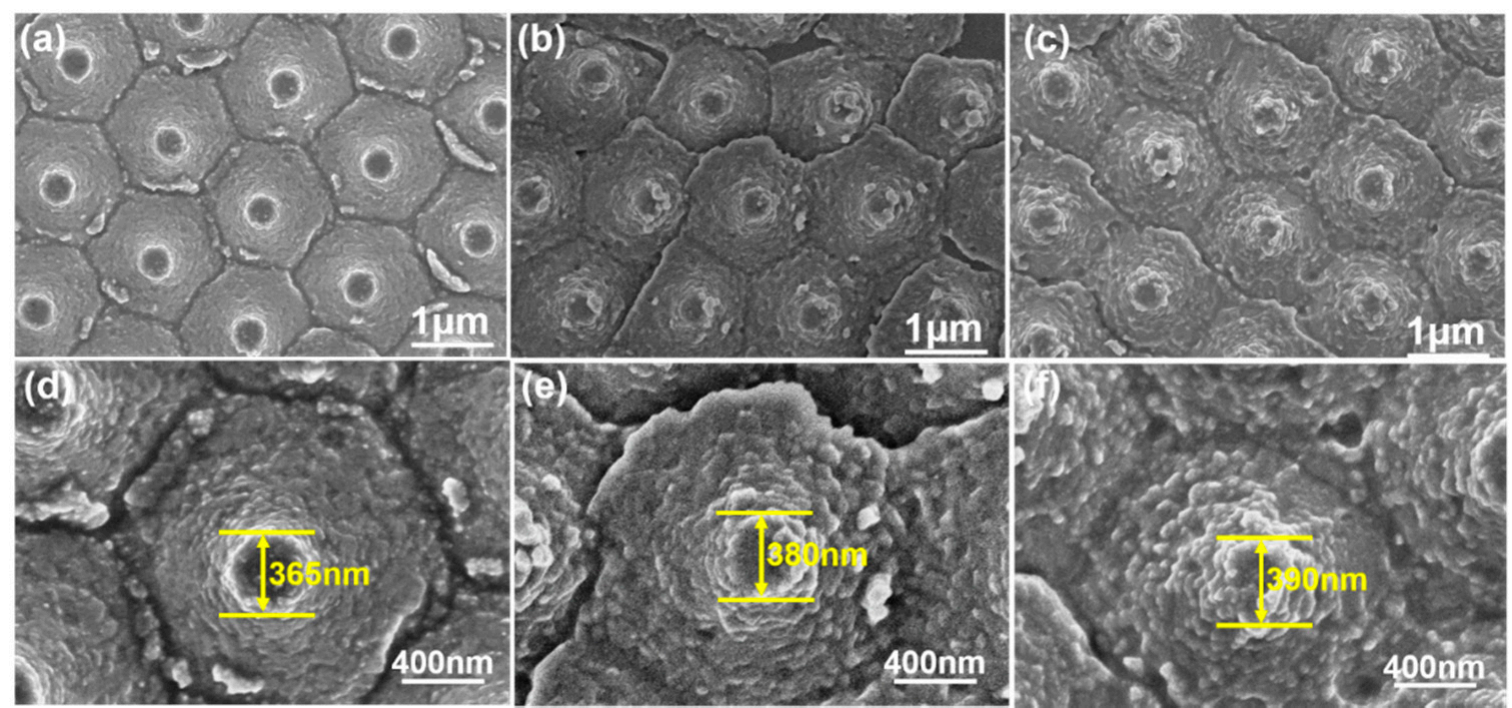

Figure 3. Low-magnification SEM images of the surface of a prepared $\mathrm{ZnO}$ seed layer on $\mathrm{Al}$ sacrificial layers of different thicknesses: (a) 120, (b) 420, and (c) $720 \mathrm{~nm}$. High-magnification SEM images of the surface of a prepared $\mathrm{ZnO}$ seed layer on Al sacrificial layers of different thicknesses: (d) 120, (e), 420, and (f) $720 \mathrm{~nm}$.

Figure $3 \mathrm{~d}-\mathrm{f}$ shows the high-magnification SEM images of the surface of the prepared $\mathrm{ZnO}$ seed layer on $\mathrm{Al}$ sacrificial layers of various thicknesses. The particle sizes of the $\mathrm{ZnO}$ seed layer for the SC-A, SC-B, and SC-C substrates were calculated using Debye-Scherrer's equation (Equation (1) below), and they were about 35, 65, and $80 \mathrm{~nm}$, respectively, where, 
in our study, $\lambda$ was $1.54 \AA$, D was the crystalline size, $B$ was the full width at half maximum (FWHM) values of the (002) plane of the $\mathrm{ZnO}$ seed layers, and $\theta$ was the diffraction angle:

$$
\mathrm{D}=\frac{0.9 \lambda}{\beta \cos \theta}
$$

These images show that the diameters of the top part of the $\mathrm{ZnO}$ seed layer were about 365, 380, and $390 \mathrm{~nm}$, respectively. Apparently, as the thickness of the Al sacrificial layer etching time increased, the etching took longer, which increased the particle sizes and the diameters of the $\mathrm{ZnO}$ seed layer. These observations could be related to the presence of the Al element. Zhang and Que found that the crystal grain size of Al-doped ZnO changed with the concentration of $\mathrm{Al}^{3+}$ ions or $\mathrm{Al}_{2} \mathrm{O}_{3}$; when the concentration of $\mathrm{Al}$ increased from 1 at $\%$ to 2 at $\%$, the crystal grain size of Al-doped $\mathrm{ZnO}$ also increased [21]. In the present study, the concentration of the residual $\mathrm{Al}$ in the $\mathrm{ZnO}$ seed layer increased with the thickness of the Al sacrificial layer. This observation proves that the amount of an Al-based impurity, such as $\mathrm{Al}(\mathrm{OH})_{3}$, that is deposited on the surface of a $\mathrm{ZnO}$ seed layer increases with the thickness of the $\mathrm{Al}$ sacrificial layer. Therefore, we believe that, as the etching time increases with the thickness of the Al sacrificial layer, the amount of the Al-based impurity also increases, which causes an increase in the particle sizes.

Figure $4 \mathrm{a}-\mathrm{c}$ shows the low magnification cross-sectional SEM images of the prepared $\mathrm{ZnO}$ seed layer on $\mathrm{Al}$ sacrificial layers of different thicknesses. The figure shows that the protrusion patterned $\mathrm{ZnO}$ seed layer had a matrix structure. Figure $4 \mathrm{~d}-\mathrm{f}$ shows highmagnification cross-sectional SEM images of the prepared $\mathrm{ZnO}$ seed layer on Al sacrificial layers of different thicknesses. The thicknesses of the $\mathrm{ZnO}$ seed layers on top of the protrusions were measured using the FIB system and determined to be 206, 184, and 180 $\mathrm{nm}$ for the SC-A, SC-B, and SC-C substrates, respectively. Figure 4 also shows an important result, which is that even the $\mathrm{KOH}$ solution could dissolve or etch the $\mathrm{ZnO}$ seed layers the etching effect can thus be neglected, because the thicknesses of all the $\mathrm{ZnO}$ seed layers were larger than $180 \mathrm{~nm}$.
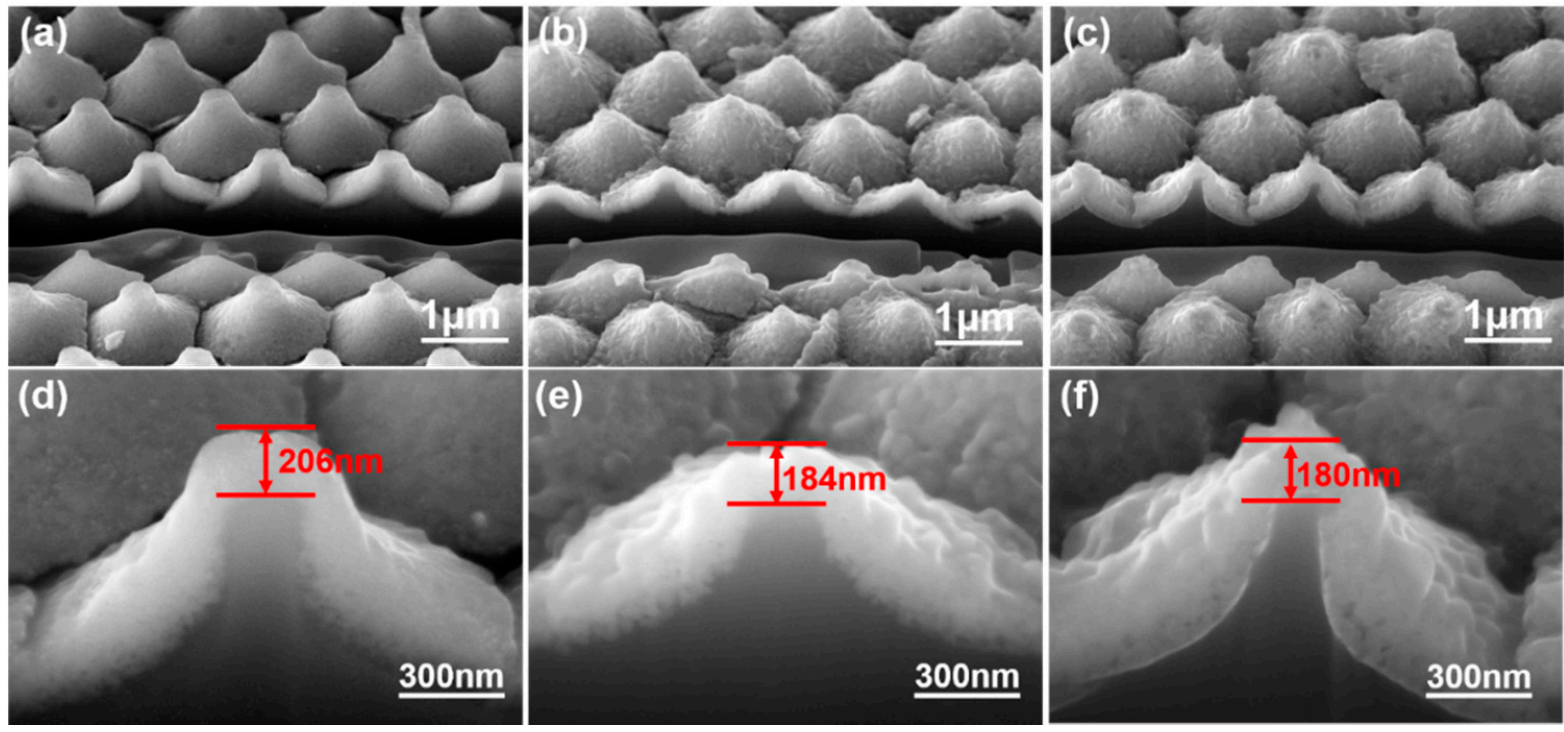

Figure 4. Low-magnification cross-sectional SEM images of the $\mathrm{ZnO}$ seed layer on $\mathrm{Al}$ sacrificial layers of different thicknesses: (a) 120, (b), 420, and (c) $720 \mathrm{~nm}$. High-magnification cross-sectional SEM images of the $\mathrm{ZnO}$ seed layer on Al sacrificial layers of different thicknesses: (d) 120, (e) 420, and (f) $720 \mathrm{~nm}$.

To prove that $\mathrm{Al}$ element was residual in the $\mathrm{ZnO}$ seed layer, EDS analyses were performed on the surfaces of the $\mathrm{ZnO}$ seed layer. Figure 5a shows the result of a SC-B substrate used in the analysis. As can be seen in Figure $5 \mathrm{a}$, the breakages between the 
seed points are filled with a white material. Figure $5 \mathrm{~b}$ shows the results of the analysis of the SC-B substrate. As Figure 5b shows, in addition to oxygen $(\mathrm{O})$, zinc $(\mathrm{Zn})$, carbon $(\mathrm{C})$, silicon ( $\mathrm{Si}$ ), and aluminum ( $\mathrm{Al}$ ) elements were detected in all $\mathrm{ZnO}$ seed layers synthesized on the SC-B substrate. The results of the EDS analyses of the SC-A and SC-C substrates were similar. The detected signals of $\mathrm{Si}$ and $\mathrm{C}$ were caused by the silicon wafer and the OE-6370HF AB optical glue. However, we believe that the detected signal of Al was caused by a residual Al-based impurity, such as $\mathrm{Al}(\mathrm{OH})_{3}$, which formed during the etching process.
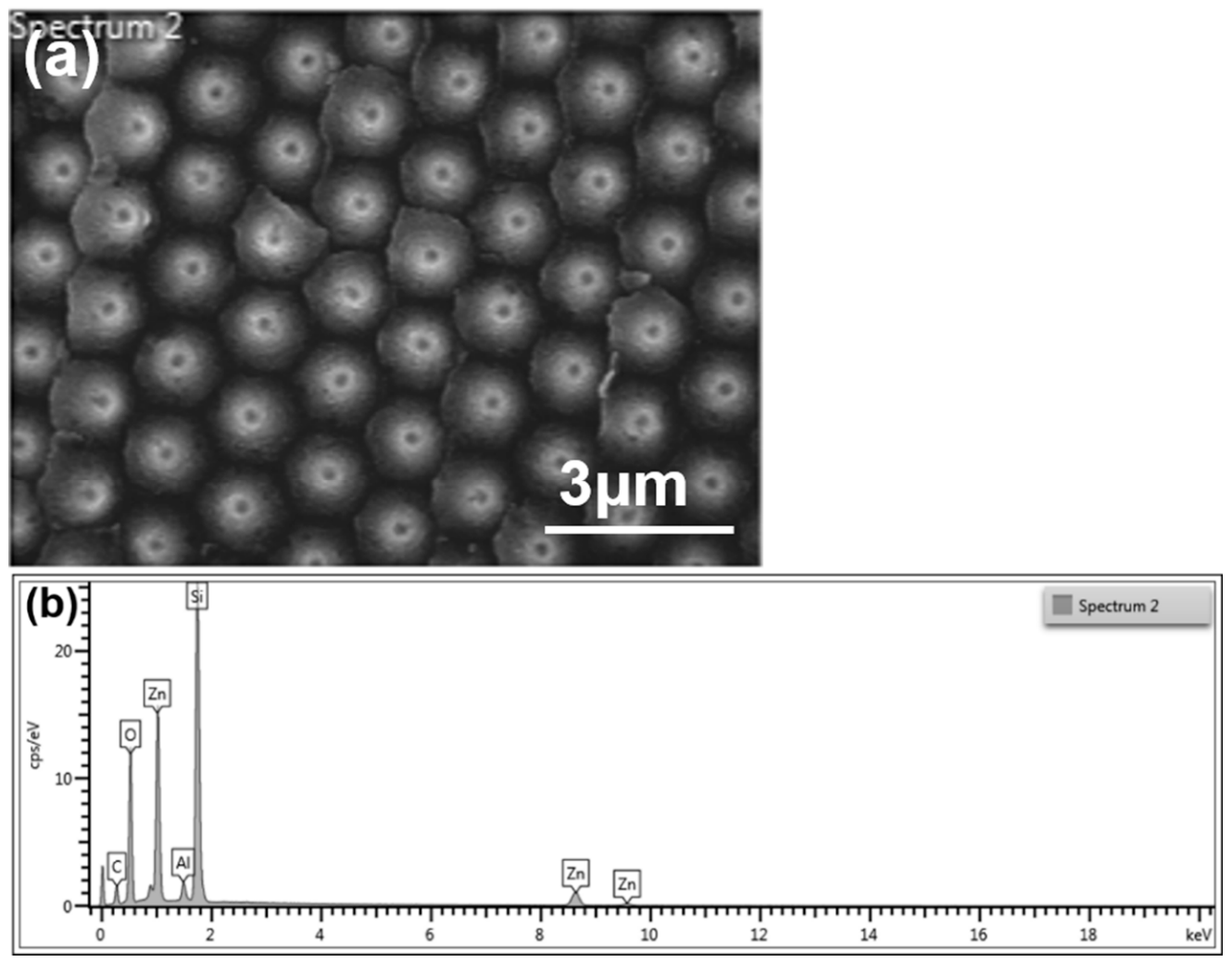

Figure 5. (a) Sample used in the EDS analyses; (b) the EDS analysis results for the SC-B substrate.

Table 1 compares the EDS results for the SC-A, SC-B, and SC-C substrates. According to the table, as the thickness of the Al sacrificial layer increased from 120 to $720 \mathrm{~nm}$, the percentage of the Al element increased from $0.97 \%$ to $3.20 \%$. These results prove that a residual Al-based impurity filled the breakages in the surfaces of the $\mathrm{ZnO}$ seed points. The results also indicate that, as the thickness of the Al sacrificial layer increased, there was a greater amount of residual Al-based impurity. Thus, an increase in the amount of the residual Al-based impurity caused an increase in the particle sizes of the $\mathrm{ZnO}$ seed layer, as shown in Figure 4d-f.

Table 1. Results of the EDA analyses of prepared $\mathrm{ZnO}$ seed layers for the three substrates. wt $\%$ and at $\%$ : percentage by weight and atomic percentage.

\begin{tabular}{lllllll}
\hline & \multicolumn{2}{c}{ SC-A } & \multicolumn{2}{c}{ SC-B } & \multicolumn{2}{c}{ SC-C } \\
\hline Element & $\mathbf{w t} \%$ & $\mathbf{a t} \%$ & $\mathbf{w t} \%$ & $\mathbf{a t} \%$ & $\mathbf{w t} \%$ & at $\%$ \\
\hline $\mathrm{O}$ & 40.04 & 72.74 & 45.32 & 75.86 & 43.45 & 74.40 \\
$\mathrm{Zn}$ & 58.99 & 26.22 & 51.69 & 21.17 & 53.35 & 22.35 \\
$\mathrm{Al}$ & 0.97 & 1.04 & 2.99 & 2.97 & 3.20 & 3.25 \\
Total & 100.0 & 100.0 & 100.0 & 100.0 & 100.0 & 100.0 \\
\hline
\end{tabular}




\subsection{The $\mathrm{ZnO}$ Nanoflower Arrays Analyses \\ 3.2.1. FESEM Analyses}

Figure 6 shows SEM images of the surface of the $\mathrm{ZnO}$ nanoflower arrays on $\mathrm{Al}$ sacrificial layers of different thicknesses with synthesis times of $10 \mathrm{~min}, 30 \mathrm{~min}$, and $60 \mathrm{~min}$, respectively. Compared with the images shown in Figures 3 and 5, these images show that the breakages between the seed points had been patched. This patching effect increased with the synthesis times of the $\mathrm{ZnO}$ nanoflower arrays. When the synthesis time was less than or equal to $30 \mathrm{~min}$, incomplete $\mathrm{ZnO}$ nanorods were observed on the surfaces of the $\mathrm{ZnO}$ nanoflower arrays synthesized on the SC-B and SC-C substrates. The diameters and heights of the $\mathrm{ZnO}$ nanorods increased with time, and, as the synthesis times were $10 \mathrm{~min}$ and $30 \mathrm{~min}$, the numbers of $\mathrm{ZnO}$ nanorods grown decreased with the thickness of the $\mathrm{Al}$ sacrificial layer. Figure $6 \mathrm{a}-\mathrm{c}$ shows that the required synthesis time of the $\mathrm{ZnO}$ nanorods increased with the thickness of the Al sacrificial layer. For example, when the synthesis time was $10 \mathrm{~min}$, the $\mathrm{ZnO}$ nanorods were readily observed on the SC-A substrate but not observed on the SC-B and SC-C substrates; when the synthesis time was $30 \mathrm{~min}$, the diameters and heights of the $\mathrm{ZnO}$ nanorods decreased with the thickness of the $\mathrm{Al}$ sacrificial layer. These results suggest that the growth rates of the $\mathrm{ZnO}$ nanorods that were synthesized on the SC-B and SC-C substrates were significantly reduced. While obtaining results of the FIB-based cross-sections analyses (reported in Section 3.2.3), when the synthesis time was $60 \mathrm{~min}$, the heights of the $\mathrm{ZnO}$ nanorods decreased with the thickness of the Al sacrificial layer. From the results provided in Table 1, we can assume that the reduced growth rate was caused by an increase in the residual Al-based impurities on the surfaces of the $\mathrm{ZnO}$ seed layers.
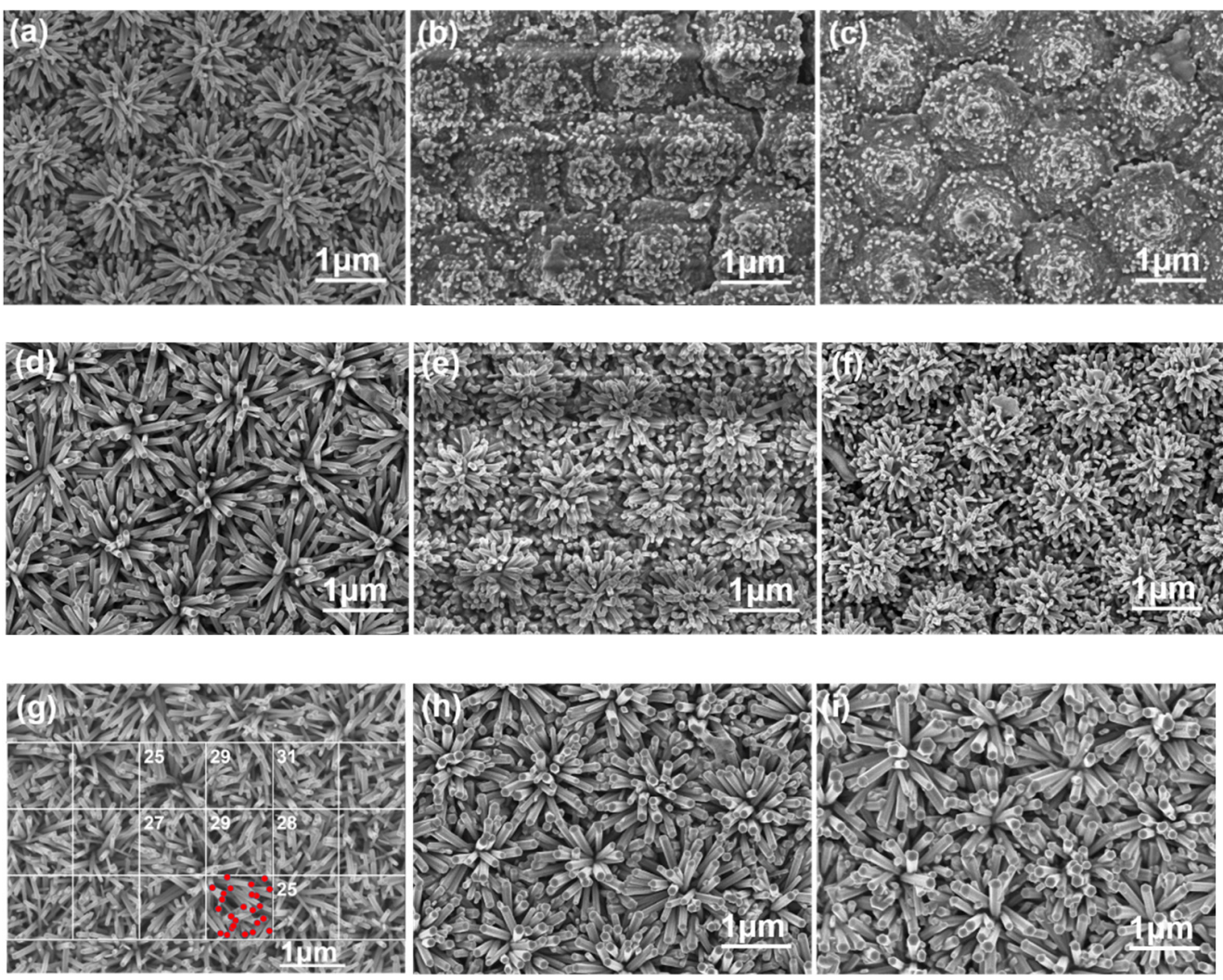

Figure 6. SEM images of the surface of the $\mathrm{ZnO}$ nanoflower arrays with a synthesis time of $10 \mathrm{~min}$ on Al sacrificial layers of different thicknesses: (a) 120, (b) 420, and (c) $720 \mathrm{~nm}$. With a synthesis time of 30 min on Al sacrificial layers of different thicknesses: (d) 120, (e) 420, and (f) $720 \mathrm{~nm}$. With a synthesis time of 60 min on Al sacrificial layers of different thicknesses: (g) 120, (h) 420, and (i) $720 \mathrm{~nm}$. 
Figure 6 shows that the $\mathrm{ZnO}$ nanorods did not only grow perpendicular to the substrates; they also grew along the surface direction of the $\mathrm{ZnO}$ seed layer, which was in the radial direction. $\mathrm{ZnO}$ nanorods grew with a flower-like structure where each petal had a single rod shape. Therefore, in this study, the $\mathrm{ZnO}$ nanorods that were synthesized on a patterned $\mathrm{ZnO}$ seed layer grew like a flower as $\mathrm{ZnO}$ nanoflower arrays. As shown in Figure 6, the synthesized $\mathrm{ZnO}$ nanorods exhibited a uniform morphology (i.e., uniform diameter and height) when the synthesis time was longer than $10 \mathrm{~min}$ for the SC-A substrate and longer than $30 \mathrm{~min}$ for the SC-B and SC-C substrates. We attribute this uniform morphology to a high growth selectivity and strong polarization along the protrusion $\mathrm{ZnO}$ seed layer that allowed the synthesized $\mathrm{ZnO}$ nanorods to form a $\mathrm{ZnO}$ nanoflower. As Figures 3 and 4 show, the prepared $\mathrm{ZnO}$ seed layer had the structure of a hexagonal array with a bump in the center of each hexagon. Because the synthesized $\mathrm{ZnO}$ nanorods grew along the vertical substrate, they readily formed the $\mathrm{ZnO}$ nanoflower arrays. The use of the patterned sapphire template enabled the $\mathrm{ZnO}$ seed layer arrays to easily form matrix structures. Therefore, the investigated technology played a crucial role in synthesizing $\mathrm{ZnO}$ nanorods in a radial direction on a patterned $\mathrm{ZnO}$ seed layer to form $\mathrm{ZnO}$ nanoflower arrays.

\subsubsection{XRD Analyses}

Various conditions were changed in order to investigate the effect of the synthesis time on the crystalline and optical properties of the synthesized $\mathrm{ZnO}$ nanoflower arrays. First, the synthesis time was changed from $10 \mathrm{~min}$ to $60 \mathrm{~min}$, the synthesis temperature was set at $90{ }^{\circ} \mathrm{C}$, and $0.2 \mathrm{M} \mathrm{Zn}\left(\mathrm{CH}_{3} \mathrm{COO}\right)_{2}$ and $0.2 \mathrm{M} \mathrm{C}_{6} \mathrm{H}_{12} \mathrm{~N}_{4}$ solutions were used. The XRD spectra of the $\mathrm{ZnO}$ nanoflower arrays that were synthesized on the SC-B substrate are shown in Figure 7 as a function of synthesis time. The $\mathrm{X}$-ray spectra for the $\mathrm{ZnO}$ nanoflower arrays that were synthesized on the SC-A and SC-C substrates were identical to the results shown in Figure 7. The diffraction peaks at the (100), (002), (101), (102), and (110) planes, which corresponded to the peaks located at $2 \theta$ values $31.78^{\circ} \sim 31.80^{\circ}, 31.38^{\circ} \sim 34.40^{\circ}, 36.18^{\circ} \sim 36.22^{\circ}$, $47.48^{\circ} \sim 47.52^{\circ}$, and $56.54^{\circ} \sim 56.58^{\circ}$ for different synthesis times, could be readily observed when the synthesis time was equal to or greater than $20 \mathrm{~min}$. When the diffraction peaks are compared with the JCPDS card number 36-1451, the results indicate that the synthesized $\mathrm{ZnO}$ nanorods in the $\mathrm{ZnO}$ nanoflower arrays had a polycrystalline growth and a wurtzite structure with an HCP array.

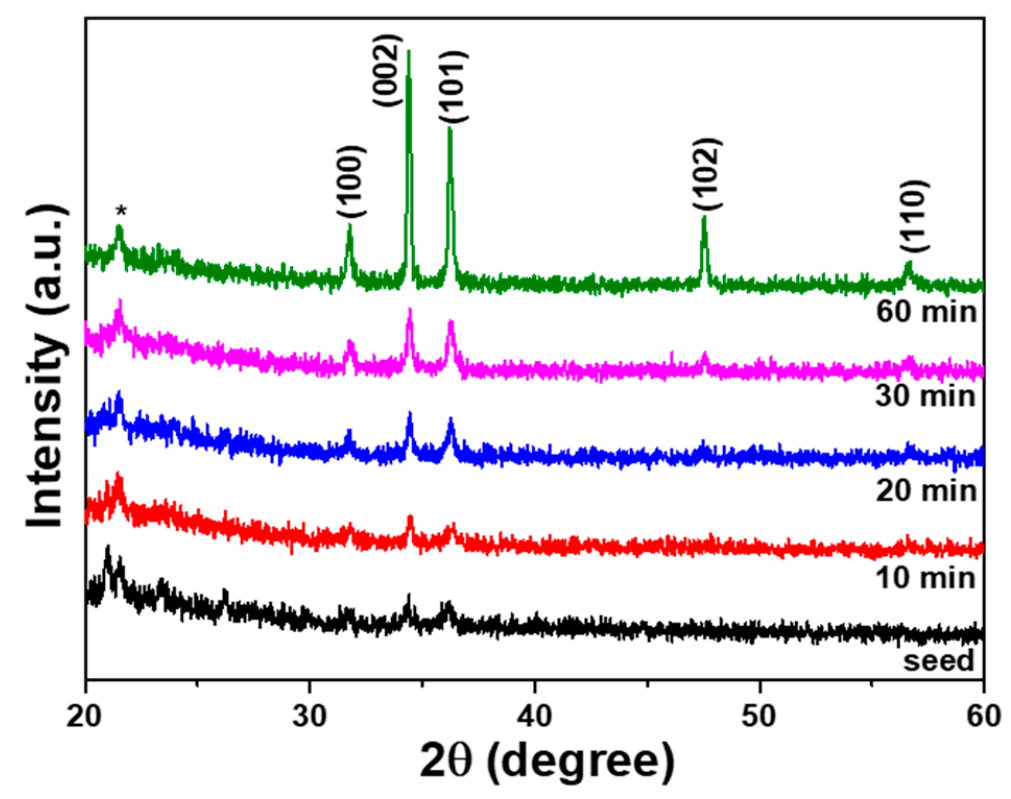

Figure 7. XRD spectra of the $\mathrm{ZnO}$ seed layer and $\mathrm{ZnO}$ nanoflower arrays on the SC-B substrate as a function of synthesis time; ${ }^{*}-\mathrm{AB}$ glue. 
The diffraction intensities of the $\mathrm{ZnO}$ nanoflower arrays in five different planes increased with synthesis time. Thus, the crystal properties of the $\mathrm{ZnO}$ nanoflower arrays were enhanced with synthesis time. The $\mathrm{ZnO}$ nanoflower arrays did not show the characteristic c-axis preferred orientation, because the $\mathrm{ZnO}$ nanoflower arrays mainly grew in the direction perpendicular to the $\mathrm{ZnO}$ seed layer and spread out like a flower, as shown in Figures 6-8. As can be seen in Figure 6b,c, for a synthesis time of $10 \mathrm{~min}$ the $\mathrm{ZnO}$ nanorods did not completely cover the $\mathrm{ZnO}$ seed layer. Therefore, the diffraction intensity of the XRD spectra for the $\mathrm{ZnO}$ nanoflower arrays was reduced. The crystalline sizes with the variations in the growth time of the $\mathrm{ZnO}$ nanoflower arrays were also calculated using Debye-Scherrer's equation. The crystalline sizes of the $\mathrm{ZnO}$ nanoflower arrays on the SC-B substrate were $11.2,8.85,10.5$, and $9.33 \mathrm{~nm}$ when the synthesis times were $10,20,40$, and $60 \mathrm{~min}$, respectively.

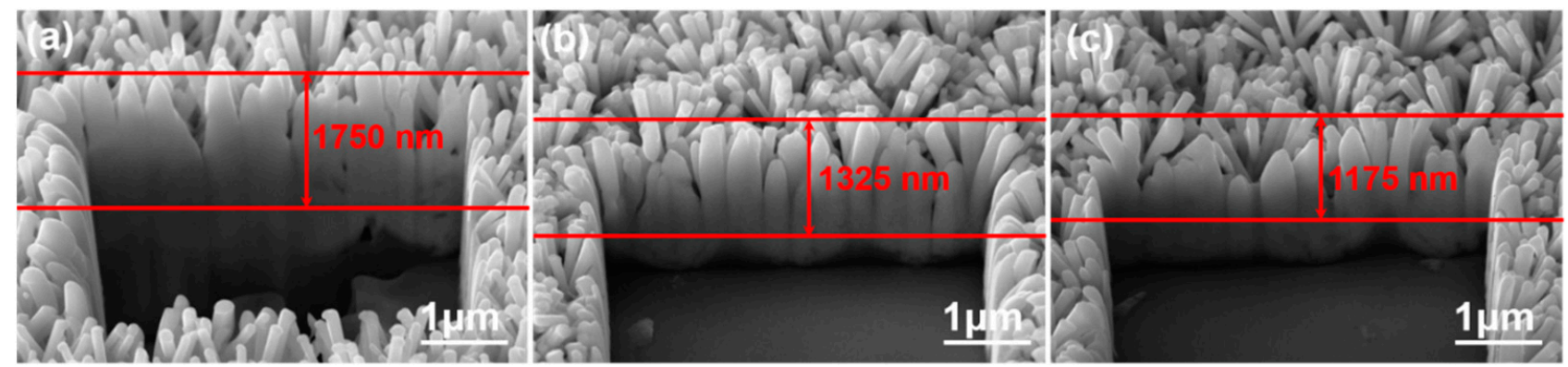

Figure 8. Cross-sectional SEM images of the $\mathrm{ZnO}$ nanoflower arrays on $\mathrm{Al}$ sacrificial layers of different thicknesses: (a) 120, (b) 420, and (c) $720 \mathrm{~nm}$.

\subsubsection{FIB-Based Cross-Sections Analyses}

Figure 8 shows cross-sectional SEM images of the $\mathrm{ZnO}$ nanoflower arrays. These images were used to measure the heights and diameters of the $\mathrm{ZnO}$ nanoflower arrays on different substrates with a synthesis time of $60 \mathrm{~min}$. After first deducting the thicknesses of the $\mathrm{ZnO}$ seed layers for the SC-A, SC-B, and SC-C substrates, which were 206, 184, and $180 \mathrm{~nm}$, the average heights of the $\mathrm{ZnO}$ nanoflower arrays were determined to be $1500 \mathrm{~nm}$ (the heights were in the range of 1405 1580 nm), $1125 \mathrm{~nm}(1045 \sim 1190 \mathrm{~nm})$, and $975 \mathrm{~nm}$ $(920 \sim 1035 \mathrm{~nm})$, respectively, and the average diameters were $90 \mathrm{~nm}$ (the diameters were in the range of $81 \sim 98 \mathrm{~nm}), 103 \mathrm{~nm}(95 \sim 110 \mathrm{~nm})$, and $115 \mathrm{~nm}(108 \sim 123 \mathrm{~nm})$, respectively. In this study, we noticed that the particle sizes of the $\mathrm{ZnO}$ seed layer increased with the thickness of the $\mathrm{Al}$ sacrificial layer, which caused the heights to decrease and the diameters to increase. $\mathrm{ZnO}$ seed layers that had large particle sizes had larger areas for the $\mathrm{Zn}\left(\mathrm{CH}_{3} \mathrm{COO}\right)_{2}$ and $\mathrm{C}_{6} \mathrm{H}_{12} \mathrm{~N}_{4}$ solutions to deposit $\mathrm{ZnO}$ on; thus, more $\mathrm{ZnO}$ nanorods could be formed at the same time. In addition, when $\mathrm{ZnO}$ nanorods were synthesized on large seed particles, they had a greater chance to merge with each other, which increased the growth rates in the vertical direction (i.e., perpendicular to the $\mathrm{ZnO}$ seed layer) and in the radial direction. Therefore, the diameter increased, and the height decreased, with the thickness of the Al sacrificial layer.

Correspondingly, the calculated aspect ratios (H/D) of the $\mathrm{ZnO}$ nanoflower arrays decreased from 16.77, to 10.9 , and to 8.48 when the SC-A, SC-B, and SC-C substrates were used. Thus, the aspect ratio of the $\mathrm{ZnO}$ nanoflower arrays was influenced by the substrates, which affected the relative synthesis rates in the vertical and radial directions. A comparison with Figure 6 shows that, as the same synthesis time was used, the heights of the $\mathrm{ZnO}$ nanoflower arrays decreased with the thickness of the $\mathrm{Al}$ sacrificial layer. Zhang and Que reported that, as the $\mathrm{Al}$ concentration increased, the height of the $\mathrm{ZnO}$ nanorods first increased, and then reached a maximum when the $\mathrm{Al}$ concentration was $1 \mathrm{at} \%$. When the $\mathrm{Al}$ concentration was greater than 1 at $\%$, the growth of the $\mathrm{ZnO}$ nanorods was inhibited and, thus, the height of the synthesized $\mathrm{ZnO}$ nanorods was reduced [21]. One reason for the 
decrease in the height of the $\mathrm{ZnO}$ nanoflower arrays is that the residual Al-based impurity increased with the thickness of the $\mathrm{Al}$ sacrificial layer (Table 1).

To estimate the density (i.e., quantity) of the $\mathrm{ZnO}$ nanoflower arrays in a unit area of $1 \mu \mathrm{m}^{2}$, the image of the $\mathrm{ZnO}$ nanoflower arrays was segmented into squares, each with an area of $1 \mu \mathrm{m}^{2}$, as shown in Figure $6 \mathrm{~g}$. At least eight squares were randomly chosen, and the density of the $\mathrm{ZnO}$ nanoflower arrays in all selected squares was estimated; the average density was determined from the estimated values. When the thickness of the substrate changed, the residual concentration of the Al-based impurity also changed, which affected the rate of the synthesis of the $\mathrm{ZnO}$ nanoflower arrays. Therefore, it was possible to determine how the thickness of the $\mathrm{Al}$ sacrificial layer affected the diameter, height, and aspect ratio of the $\mathrm{ZnO}$ nanoflower arrays. The average densities of the $\mathrm{ZnO}$ nanorods in the $\mathrm{ZnO}$ nanoflower arrays that were synthesized on the SC-A, SC-B, and SC-C substrates were $28 \mu \mathrm{m}^{-2}, 20 \mu \mathrm{m}^{-2}$, and $18 \mu \mathrm{m}^{-2}$, respectively (Table 2). The estimated average diameters, average heights, and average densities of the $\mathrm{ZnO}$ nanorods in the $\mathrm{ZnO}$ nanoflower arrays were used to calculate the total volume $(\mathrm{V})$ in $\mathrm{nm}^{3}$, the total surface area (S) in $\mathrm{nm}^{2}$, and the $\mathrm{S} / \mathrm{V}$ ratio. The results are given in Table 2 for the different substrates with a synthesis time of $60 \mathrm{~min}$.

Table 2. Diameter (D), height $(\mathrm{H})$, aspect ratio (H/D), density, total surface area (S), total volume (V), and $\mathrm{S} / \mathrm{V}$ ratio of $\mathrm{ZnO}$ nanoflower arrays on different substrates with a synthesis time of $60 \mathrm{~min}$.

\begin{tabular}{cccc}
\hline Substrate & SC-A & SC-B & SC-C \\
\hline Diameter $(\mathrm{nm})$ & 90 & 103 & 115 \\
Height $(\mathrm{nm})$ & 1500 & 1150 & 975 \\
Aspect ratio $(\mathrm{H} / \mathrm{D})$ & 16.7 & 11.0 & 8.12 \\
Density $\left(\mu \mathrm{m}^{-2}\right)$ & $28 \pm 3$ & $20 \pm 2$ & $18 \pm 2$ \\
Total surface area $\left(\mathrm{nm}^{2}\right)$ & $1.20 \times 10^{7}$ & $7.76 \times 10^{6}$ & $6.82 \times 10^{6}$ \\
Total volume $\left(\mathrm{nm}^{3}\right)$ & $2.67 \times 10^{8}$ & $1.99 \times 10^{8}$ & $1.98 \times 10^{8}$ \\
S/V ratio & $4.51 \times 10^{-2}$ & $3.90 \times 10^{-2}$ & $3.44 \times 10^{-2}$ \\
\hline
\end{tabular}

\subsubsection{Photoluminescence of the $\mathrm{ZnO}$ Nanoflower Arrays}

Figure 9 shows the PL spectra of the $\mathrm{ZnO}$ seed layer and the $\mathrm{ZnO}$ nanoflower arrays that were synthesized on the SC-B substrate as a function of the synthesis time. As Figure 9 displays, all the PL spectra of the $\mathrm{ZnO}$ nanoflower arrays were comprised of a high-intensity emission band, which was centered at 381.0, 380.2, 379.6, and $379.2 \mathrm{~nm}$ (UV light, $\mathrm{I}_{\mathrm{UV}}$ ). This band was mainly caused by the near-band-edge electron transition between the valence band and the conduction band [22], and a low-intensity broad emission band from 420 to $600 \mathrm{~nm}$ (green light, $\mathrm{I}_{\mathrm{G}}$ ). The emission intensities of the $\mathrm{ZnO}$ nanoflower arrays at the broad emission band of 420 600 nm were lower than those of the $\mathrm{ZnO}$ seed layer. The full width at half maximum (FWHM) values for the spectra shown in Figure 9 for $\mathrm{ZnO}$ nanoflower arrays with synthesis times of 10,20,30, and $60 \mathrm{~min}$ were 22.2, 18.4, 17.8, and $16.3 \mathrm{~nm}$, respectively. Lin et al. found that the sharp UV light emission peak at $384 \mathrm{~nm}$ could be decomposed into three emission peaks, which were centered at 384, 402, and $424 \mathrm{~nm}$. The peaks centered at 402 and $424 \mathrm{~nm}$ were the two donor states $\left(E_{d 1}\right.$ and $\left.E_{d 2}\right)$, which indicate that the hollow $\mathrm{ZnO}$ nanoflower arrays were n-type semiconductors, and the electron transitions from the $E_{d 1}$ and $E_{d 2}$ to the valence band were related to the energies 3.08 and $2.92 \mathrm{eV}$, and they would release blue light emissions [23]. We believe that the reason for the decrease in the FWHM values at the IUv peaks was the decrease of the intensities in the two donor states. 

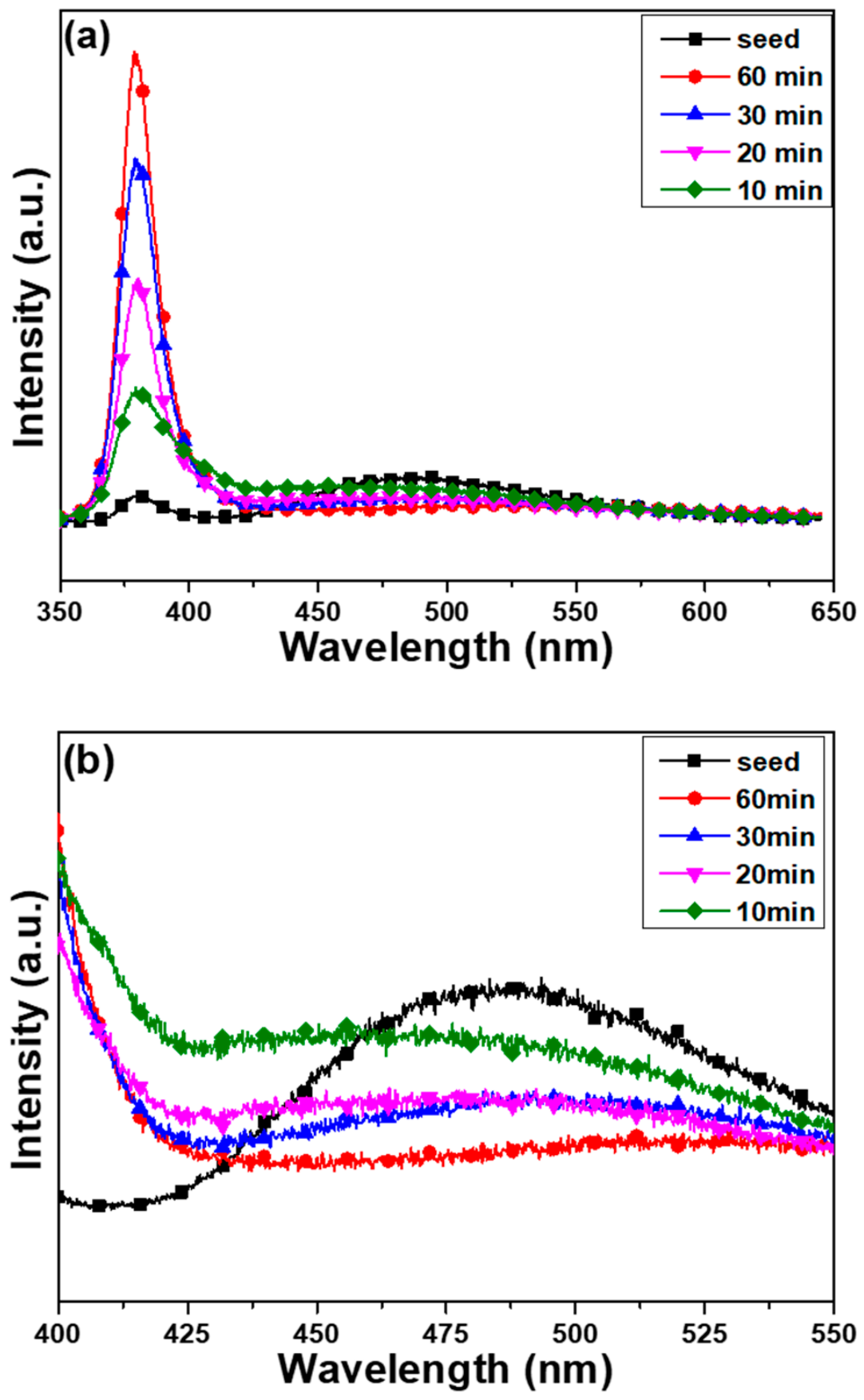

Figure 9. The PL spectra of the $\mathrm{ZnO}$ seed layer and $\mathrm{ZnO}$ nanoflower arrays on the SC-B substrate as a function of synthesis time: (a) in the wide range of 350-650 $\mathrm{nm}$ and (b) in the narrow range of 400-550 nm.

The broad visible emission band corresponds to the transitions between the near-bandedge and the local levels, which are caused by intrinsic defects that exist in the synthesized $\mathrm{ZnO}$ nanomaterials [24], or corresponds to the electron transitions between the valence band and the deep levels, where the deep levels are ascribed to the oxygen vacancies, structural defects, Zn residues, and impurities [23,25]. Examples of intrinsic defects include zinc vacancy $\left(\mathrm{V}_{\mathrm{Zn}}\right.$; bandgap energy $(E g)=3.06 \mathrm{eV}$; and emission light $\left.\sim 405 \mathrm{~nm}\right)$, interstitial zinc $\left(\mathrm{Zn}_{\mathrm{i}} ; E \mathrm{E}=2.90 \mathrm{eV}\right.$; and emission light $\left.\sim 428 \mathrm{~nm}\right)$, antisite defect $\left(\mathrm{O}_{\mathrm{Zn}} ; E \mathrm{~g}=2.38 \mathrm{eV}\right.$; and emission light $\sim 521 \mathrm{~nm})$, interstitial oxygen $\left(\mathrm{O}_{\mathrm{i}} ; E \mathrm{Eg}=2.28 \mathrm{eV}\right.$; and emission light $\left.\sim 544 \mathrm{~nm}\right)$, and oxygen vacancy $\left(\mathrm{V}_{\mathrm{O}} ; E \mathrm{~g}=1.62 \mathrm{eV}\right.$; and emission light $\left.\sim 765 \mathrm{~nm}\right)$ [24]. Therefore, the emission of $\mathrm{I}_{\mathrm{G}}$ is believed to be caused by combinations of different defects at local levels, 
including an interstitial oxygen defect $(\sim 544 \mathrm{~nm})$ and an antisite defect $(\sim 521 \mathrm{~nm})$ in the $\mathrm{ZnO}$ seed layer and $\mathrm{ZnO}$ nanoflower arrays.

Figure 9 a shows that the emission intensity of $\mathrm{I}_{\mathrm{UV}}$ increased, while the emission intensity of $\mathrm{I}_{\mathrm{G}}$ decreased with the synthesis time of the $\mathrm{ZnO}$ nanoflower arrays. In addition, the $\mathrm{I}_{\mathrm{UV}}$ values of the $\mathrm{ZnO}$ nanoflower arrays were greater than those of the $\mathrm{ZnO}$ seed layer; correspondingly, the $\mathrm{I}_{\mathrm{G}}$ values of the $\mathrm{ZnO}$ nanoflower arrays were smaller than those of the $\mathrm{ZnO}$ seed layer. When the synthesis time increased from $10 \mathrm{~min}$ to $60 \mathrm{~min}$, the intensity of $\mathrm{I}_{\mathrm{G}}$ decreased from 170 to 83 (a.u.), and the intensity of $\mathrm{I}_{\mathrm{UV}}$ increased from 594 to 2068; the $\mathrm{I}_{\mathrm{G}} / \mathrm{I}_{\mathrm{UV}}$ ratio decreased from 0.285 to 0.040 . Table 3 compares the $\mathrm{I}_{\mathrm{UV}}$ values, $\mathrm{I}_{\mathrm{G}}$ values, and $\mathrm{I}_{\mathrm{G}} / \mathrm{I}_{\mathrm{UV}}$ ratios of the $\mathrm{ZnO}$ nanoflower arrays with different substrates and synthesis times. When the images of the $\mathrm{ZnO}$ nanoflower arrays shown in Figure 6 are compared with the variations in the PL spectra shown in Figure 9a, the results prove that the synthesis time is an important factor that affects the PL properties of the synthesized $\mathrm{ZnO}$ nanoflower arrays. It is noted that the PL properties of the $\mathrm{ZnO}$ nanoflower arrays that were synthesized on the SC-A and SC-C substrates showed the same trends as the $\mathrm{ZnO}$ nanoflower arrays that were synthesized on the SC-B substrate.

Table 3. Variations in the $\mathrm{I}_{\mathrm{UV}}$ and $\mathrm{I}_{\mathrm{G}}$ values and the $\mathrm{I}_{\mathrm{G}} / \mathrm{I}_{\mathrm{UV}}$ ratio of the $\mathrm{ZnO}$ nanoflower arrays with different synthesis times and substrates.

\begin{tabular}{cccccccccc}
\hline & \multicolumn{3}{c}{ SC-A } & & & SC-B & & & SC-C \\
\hline $\begin{array}{c}\text { Time } \\
(\mathbf{m i n})\end{array}$ & $\mathbf{I}_{\mathbf{U V}}$ & $\mathbf{I}_{\mathbf{G}}$ & $\mathbf{I}_{\mathbf{G}} / \mathbf{I}_{\mathbf{U V}}$ & $\mathbf{I}_{\mathbf{U V}}$ & $\mathbf{I}_{\mathbf{G}}$ & $\mathbf{I}_{\mathbf{G}} / \mathbf{I}_{\mathbf{U V}}$ & $\mathbf{I}_{\mathbf{U V}}$ & $\mathbf{I}_{\mathbf{G}}$ & $\mathbf{I}_{\mathbf{G}} / \mathbf{I}_{\mathbf{U V}}$ \\
\hline 10 & 1156 & 337 & 0.291 & 594 & 170 & 0.285 & 581 & 145 & 0.249 \\
20 & 1804 & 263 & 0.145 & 1074 & 119 & 0.110 & 971 & 127 & 0.130 \\
30 & 2161 & 257 & 0.119 & 1597 & 116 & 0.072 & 1275 & 110 & 0.086 \\
60 & 2597 & 163 & 0.062 & 2068 & 83 & 0.040 & 1522 & 49 & 0.032 \\
\hline
\end{tabular}

It is well known that the crystal quality of $\mathrm{ZnO}$ nanoflower arrays is closely associated with the intensity of the near-band-edge emission [26]. Both the antisite defect and the interstitial oxygen defect have close relativities with the emission intensity in the range of $420 \sim 575 \mathrm{~nm}$ [26]. As Figure 9 shows, the emission intensities of the $\mathrm{ZnO}$ nanoflower arrays at the broad emission band of $420 \sim 575 \mathrm{~nm}$ were lower than that of the $\mathrm{ZnO}$ seed layer; however, the emission intensities of the $\mathrm{ZnO}$ nanoflower arrays at the strong emission peak of $\sim 381 \mathrm{~nm}$ were higher than the emission intensities of the $\mathrm{ZnO}$ seed layer. These results suggest that different defects existed in the prepared $\mathrm{ZnO}$ seed layer and contributed to its poor crystal quality, as shown in Figures 2 and 7 . Therefore, the PL property of the $\mathrm{ZnO}$ nanoflower arrays depended on the synthesis time, considering the fact that their crystal quality improved to a certain extent with the synthesis time.

The greater the amount of antisite defects and interstitial oxygen defects that existed in the $\mathrm{ZnO}$ seed layer and $\mathrm{ZnO}$ nanoflower arrays, the stronger the emission intensity of $\mathrm{I}_{\mathrm{G}}$ in the broad emission band of $420 \sim 575 \mathrm{~nm}$ was. In general, the maximum emission intensity of $\mathrm{I}_{\mathrm{G}}$ can be used to judge the crystal quality of $\mathrm{ZnO}$ nanomaterials, because it indicates defects. Figure $9 \mathrm{~b}$ shows that the zinc vacancy defect, which emits light at $\sim 405 \mathrm{~nm}$, decreased with the synthesis time, although the interstitial zinc defect, which emits light at $\sim 428 \mathrm{~nm}$, was not observed in the $\mathrm{ZnO}$ seed layer or $\mathrm{ZnO}$ nanoflower arrays. The figure also shows that the emission peak of the broad emission band for the $\mathrm{ZnO}$ seed layer was located at $486 \mathrm{~nm}$ and the emission peak of the broad emission band for the $\mathrm{ZnO}$ nanoflower arrays shifted from 462 to $537 \mathrm{~nm}$ as the synthesis time increased from $10 \mathrm{~min}$ to $60 \mathrm{~min}$. These results indicate that when the $\mathrm{ZnO}$ nanoflower arrays were synthesized on a patterned $\mathrm{ZnO}$ seed layer, the antisite defects and the interstitial zinc defects could be repaired during the synthesis of the $\mathrm{ZnO}$ nanoflower arrays. However, the repair rate of the antisite defects was lower than that of the interstitial zinc defects, as the wavelength for the maximum emission intensity shifted to a higher value. The decreases in the two 
defects over time prove that the crystal qualities of $\mathrm{ZnO}$ nanoflower arrays were enhanced with the synthesis time. Thus, $\mathrm{ZnO}$ nanoflower arrays with a high emission intensity of IUV were successfully obtained when the synthesis time was extended.

The results of this study prove that when different synthesis times were used, there were fewer defects, shown as $\mathrm{I}_{\mathrm{G}}$, in the $\mathrm{ZnO}$ nanoflower arrays than in the $\mathrm{ZnO}$ seed layer; the emission intensities of $\mathrm{I}_{\mathrm{UV}}$ from the $\mathrm{ZnO}$ nanoflower arrays were also weaker than those from the $\mathrm{ZnO}$ seed layer. Figure 10 shows a comparison of the PL spectra of the $\mathrm{ZnO}$ nanoflower arrays with a synthesis time of $60 \mathrm{~min}$ on different substrates. The emission intensities of both $\mathrm{I}_{\mathrm{UV}}$ and $\mathrm{I}_{\mathrm{G}}$ increased with synthesis time. Table 2 shows that when the synthesis time was $60 \mathrm{~min}$, the diameter, height, aspect ratio, density, total surface area, and total volume decreased with the thickness of the Al sacrificial layer. The contacting surface size of the $\mathrm{ZnO}$ nanoflower arrays determined the volume that received the excitation laser light and the volume that emitted the PL spectra. Therefore, the total surface area was the most important factor that affects the emission intensity. When Figure 6 and the results in Table 2 are compared, we observe that the total surface area of the $\mathrm{ZnO}$ nanoflower arrays decreased with the thickness of the $\mathrm{Al}$ sacrificial layer. Figure 11 shows the emission intensities of $\mathrm{I}_{\mathrm{UV}}$ of the $\mathrm{ZnO}$ nanoflower arrays as a function of the synthesis time and thickness of the $\mathrm{Al}$ sacrificial layer. This figure shows that, for the same synthesis time, the emission intensity of $\mathrm{I}_{\mathrm{UV}}$ decreased with a decrease in thickness of the Al sacrificial layer. These results match the results shown in Figure 6. Thus, a comparison of the variations of the PL spectra shown in Figures 10 and 11, combined with the results in Table 3, proves that the $\mathrm{Al}$ sacrificial layer was another important factor that affected the PL properties of the $\mathrm{ZnO}$ nanoflower arrays.

The drawings of the UV-visible absorption spectroscopy of the $\mathrm{ZnO}$ nanoflower arrays for samples with the synthesis time of $60 \mathrm{~min}$ and Al sacrificial layers of 120, 240, and $720 \mathrm{~nm}$ are shown in Figure 12a, and their Tauc plots corresponding to each UV-visible spectrum are shown in Figure 12b. UV-visible absorption spectra of the ZnO nanoflower arrays revealed the optical absorption in the UV region, which could be recognized by the migration of electrons from the valance band to the conduction band [18,27]. UV-visible spectra revealed that their absorption rates decreased with the thickness of the Al sacrificial layer. The calculated band gaps for samples synthesized on the Al sacrificial layer with the thicknesses of 120, 360, and $720 \mathrm{~nm}$ were 3.026, 3.126, and $3.171 \mathrm{eV}$, respectively. To explore the defects' states and charge carrier dynamics, the results in Figure 12 can be compared with the PL spectra shown in Figure 10. All the PL spectra of the $\mathrm{ZnO}$ nanoflower arrays showed one major peak of band edge emission at around $379-381 \mathrm{~nm}$ and one broad hump in the visible region $420 \sim 600 \mathrm{~nm}$. The decrease of the emission intensity in the visible region suggests a reduction in the defect density states in the $\mathrm{ZnO}$ nanoflower arrays.

For further discussing the effect of the thickness of the Al sacrificial layer, we used an X-ray photoelectron spectroscopy (XPS) technique to measure the chemical-bonding state of oxygen. These measured results were used to find the relationship between the defects caused by the different substrates and the optical properties of the $\mathrm{ZnO}$ nanoflower arrays. The drawings of the $\mathrm{O}_{1 \mathrm{~s}}$ peak of the $\mathrm{ZnO}$ nanoflower arrays are of samples with a synthesis time of $60 \mathrm{~min}$ and $\mathrm{Al}$ sacrificial layers of 120 and $720 \mathrm{~nm}$. The typical surface $\mathrm{O}_{1 \mathrm{~s}}$ peaks of the $\mathrm{ZnO}$ nanoflower arrays were centered at $530.1 \pm 0.1 \mathrm{eV}$ and fitted by three Gaussian components of $\mathrm{O}_{\mathrm{I}}, \mathrm{O}_{\mathrm{II}}$, and $\mathrm{O}_{\mathrm{III}}$ peaks, as Figure $13 \mathrm{a}, \mathrm{b}$ shows. The $\mathrm{O}_{1 \mathrm{~s}}$ peak was divided into three peaks, $\mathrm{O}_{\mathrm{I}}, \mathrm{O}_{\mathrm{II}}$, and $\mathrm{O}_{\mathrm{III}}$, which were centered at $529.8 \pm 0.1 \mathrm{eV}, 530.3 \pm$ $0.1 \mathrm{eV}$, and $532.1 \pm 0.1 \mathrm{eV}$, respectively. For the $\mathrm{ZnO}$ nanoflower arrays, the bond energy for the component of the $\mathrm{O}_{\text {I }}$ peak was caused by the $\mathrm{Zn}^{2+}{ }_{-} \mathrm{O}^{2-}$ bond, the bond energy for the component of the $\mathrm{O}_{\text {II }}$ peak was caused by the oxygen vacancies, and the bond energy for the component of the $\mathrm{O}_{\text {III }}$ peak was caused by the chemical absorption of oxygen on the surfaces [28]. 


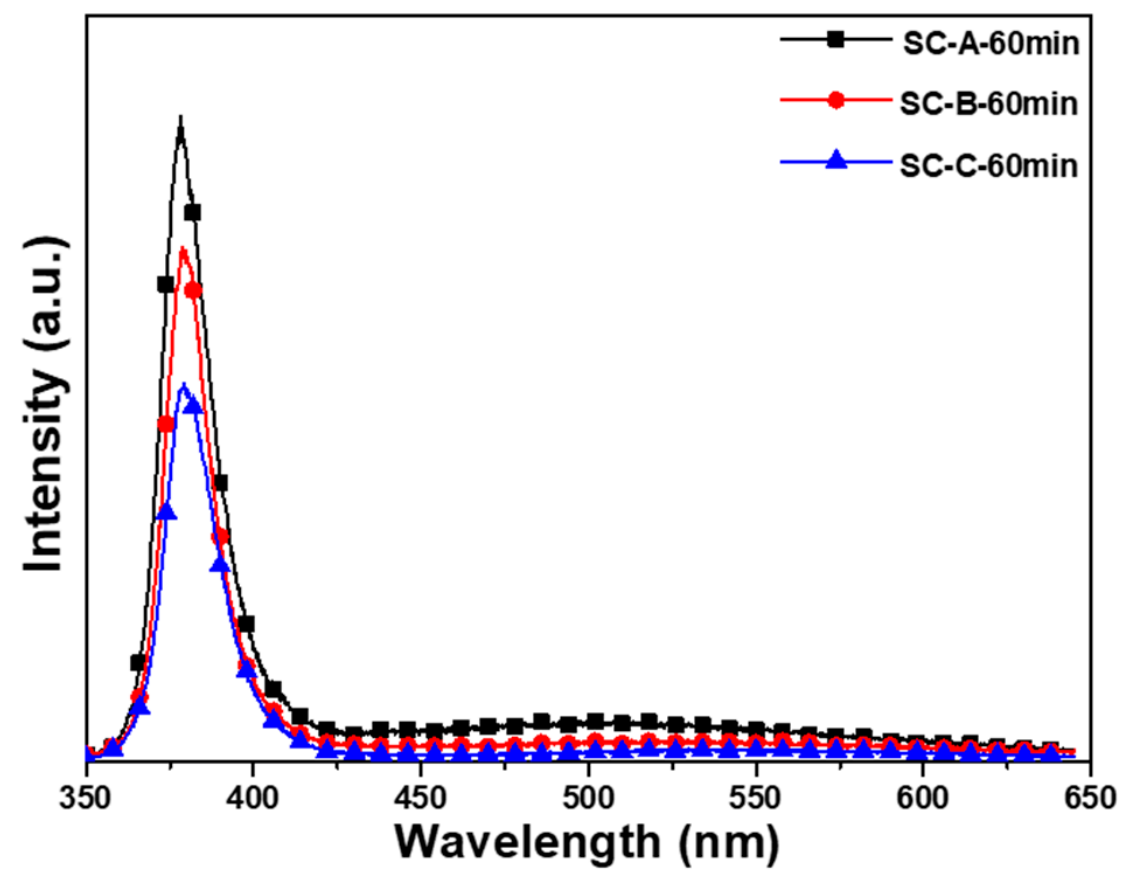

Figure 10. The PL spectra of the $\mathrm{ZnO}$ nanoflower arrays with a synthesis time of 60 min on different substrates.

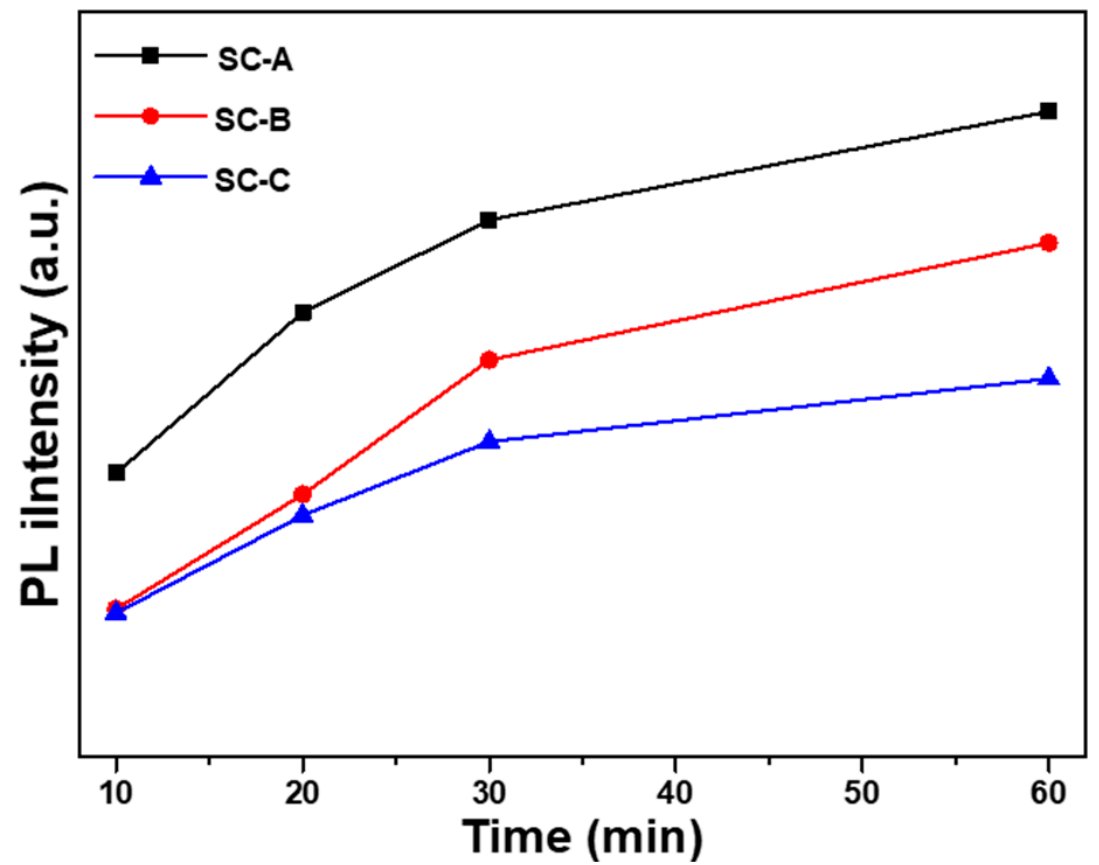

Figure 11. Emission intensities of $\mathrm{I}_{\mathrm{UV}}$ of the $\mathrm{ZnO}$ nanoflower arrays using different synthesis times and substrates. 

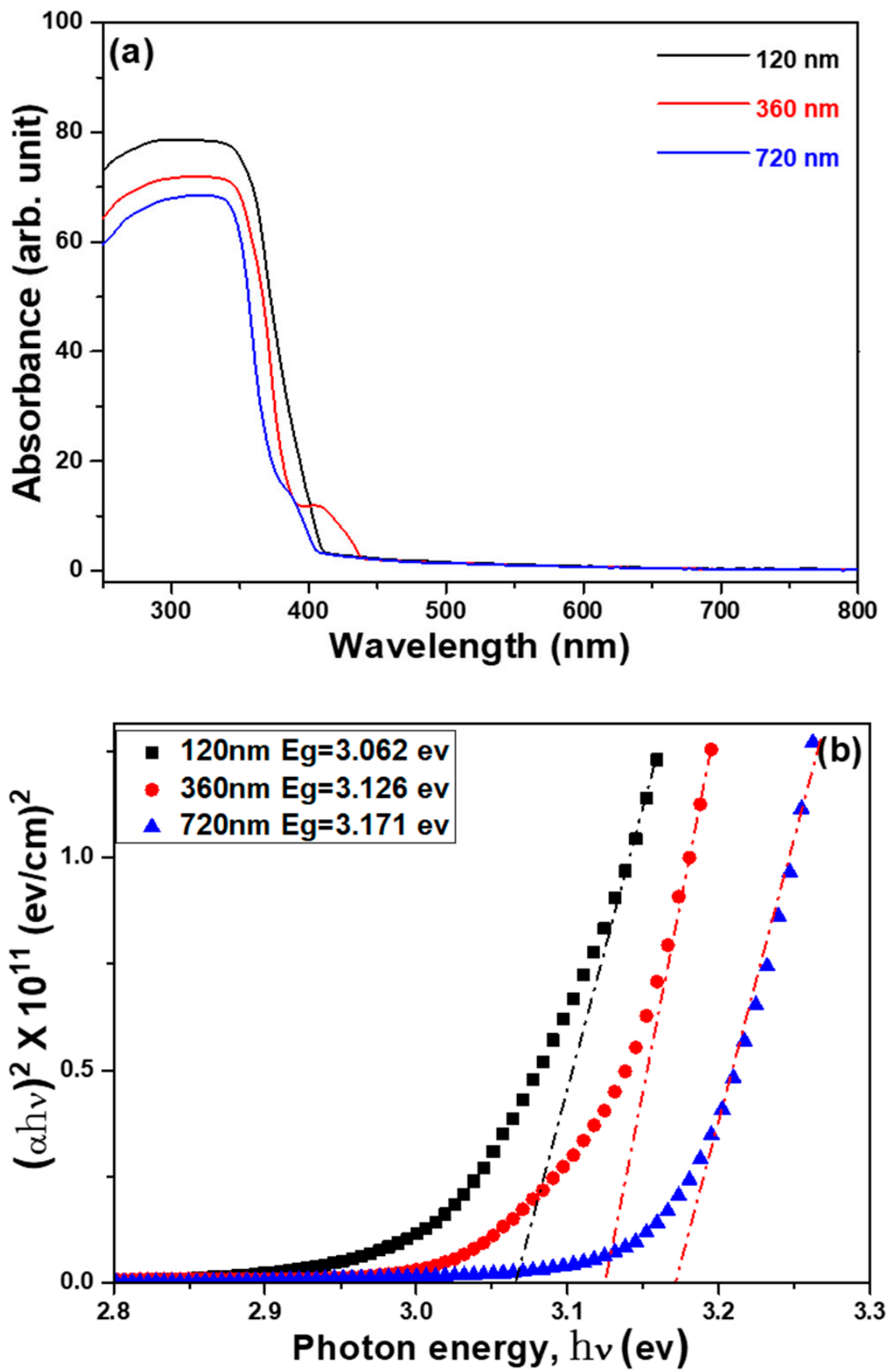

Figure 12. (a) UV-visible absorption spectra and (b) Tauc plots from UV-visible absorption spectroscopy of the $\mathrm{ZnO}$ nanoflower arrays using different substrates. 

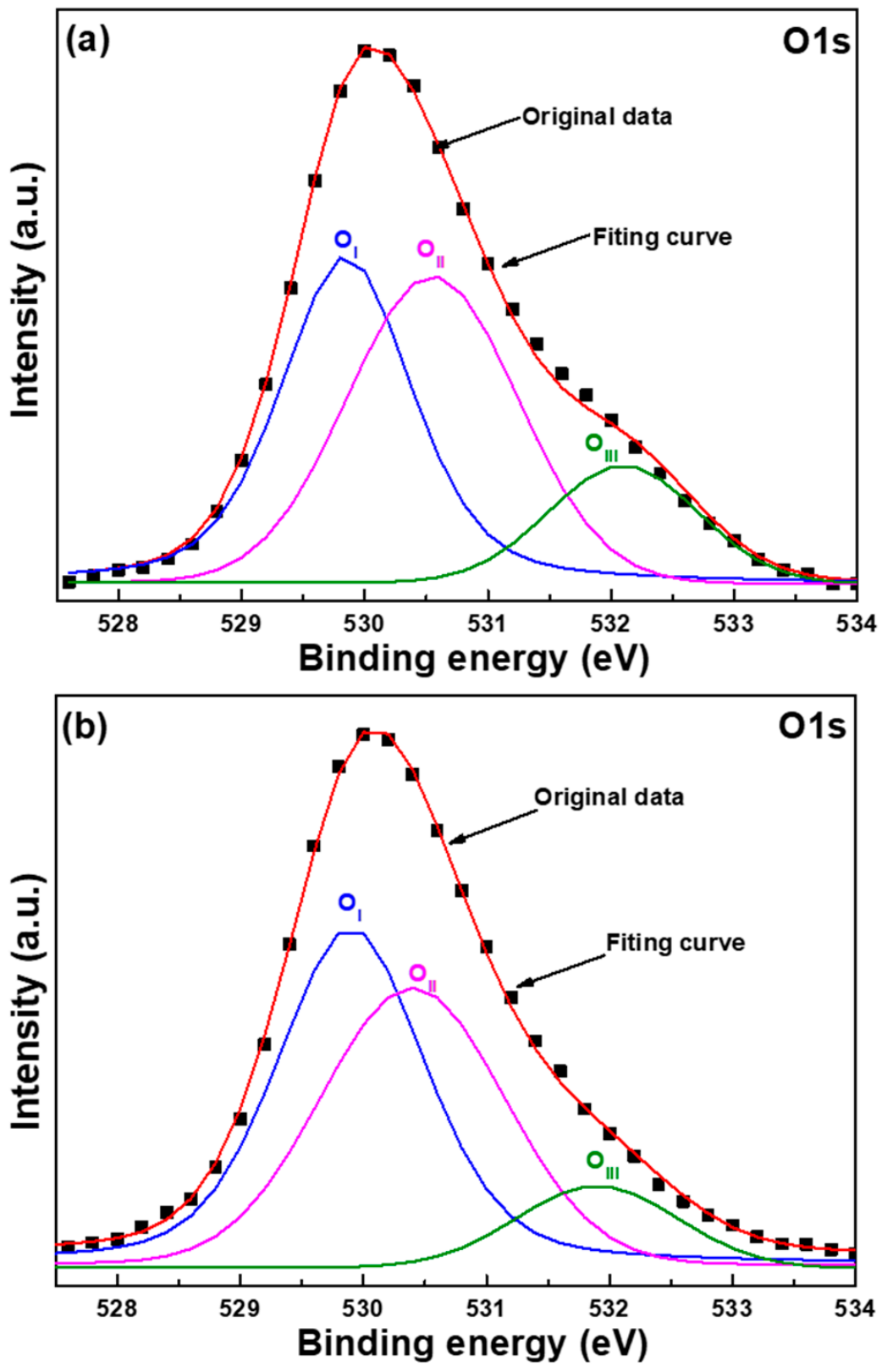

Figure 13. The drawings of $\mathrm{O}_{1 \mathrm{~s}}$ peak of the $\mathrm{ZnO}$ nanoflower arrays using different substrates and $\mathrm{Al}$ sacrificial layers of (a) $120 \mathrm{~nm}$ and (b) $720 \mathrm{~nm}$.

The areas of the $\mathrm{O}_{1 \mathrm{~s}}$ peaks measured according to the XPS spectra of the $\mathrm{ZnO}$ nanoflower arrays are compared in Table 4 as a function of the thickness of the Al sacrificial layer. As the thickness of the $\mathrm{Al}$ sacrificial layer of the $\mathrm{ZnO}$ nanoflower arrays increased from 120 to $720 \mathrm{~nm}$, the area of the $\mathrm{O}_{\text {I }}$ peak increased from $45.26 \%$ to $48.54 \%$, the area of the $\mathrm{O}_{\text {II }}$ peak decreased from $43.06 \%$ to $40.93 \%$, and the area of the $\mathrm{O}_{\text {III }}$ peak decreased from $11.68 \%$ to $10.54 \%$. Apparently, the area of the $\mathrm{O}_{\mathrm{II}}$ peak of the $\mathrm{ZnO}$ nanoflower arrays decreased with the increase in the thickness of the $\mathrm{Al}$ sacrificial layer, which proves that the oxygen vacancies of the $\mathrm{ZnO}$ nanoflower arrays decrease with the increase in the thickness of the Al sacrificial layer. These results also suggest that the defects in $\mathrm{ZnO}$ nanoflower arrays decrease with the increase in the thickness of the Al sacrificial layer. Because the oxygen vacancies decreased with the thickness of the $\mathrm{Al}$ sacrificial layer, these results indirectly prove that the intensity of the $\mathrm{I}_{\mathrm{G}}$ value of $\mathrm{ZnO}$ nanoflower arrays decreases with the thickness of the Al sacrificial layer, which matches the measured results shown in Figure 10. 
Table 4. Areas of $\mathrm{O}_{1 \mathrm{~s}}$ peaks of $\mathrm{ZnO}$ nanoflower arrays as a function of thickness of the $\mathrm{Al}$ sacrificial layers.

\begin{tabular}{cccc}
\hline Thickness of Al & $\mathbf{1 2 0}$ & $\mathbf{3 6 0}$ & $\mathbf{7 2 0}$ \\
\hline $\mathrm{O}_{\mathrm{I}}$ & $45.26 \%$ & $46.67 \%$ & $48.54 \%$ \\
$\mathrm{O}_{\mathrm{II}}$ & $43.06 \%$ & $41.96 \%$ & $40.92 \%$ \\
$\mathrm{O}_{\text {III }}$ & $11.68 \%$ & $11.37 \%$ & $10.54 \%$ \\
\hline
\end{tabular}

\section{Conclusions}

In this study, $\mathrm{ZnO}$ seed layers that had a protrusion patterned array structure were prepared on $\mathrm{Al}$ sacrificial layers of different thicknesses. For Al sacrificial layers that were 120, 420, and $720 \mathrm{~nm}$ thick, the particle sizes of the $\mathrm{ZnO}$ seed layers were about 35, 65, and $80 \mathrm{~nm}$, the diameters of the top parts of the $\mathrm{ZnO}$ seed layers were about 365, 380, and $390 \mathrm{~nm}$, and the $\mathrm{ZnO}$ seed layers were 206, 184, and $180 \mathrm{~nm}$ thick, respectively. The SEM and EDS analyses indicated that when a thick Al sacrificial layer was deposited, a longer etching time was needed and more Al-based impurity was residual. The heights of the $\mathrm{ZnO}$ nanoflower arrays decreased and the diameters increased with the thicknesses of the sacrificial Al layer. The results also indicated that the diameter increased and the height, aspect ratio, density, total surface area (S), total volume $(\mathrm{V}), \mathrm{S} / \mathrm{V}$ ratio, $\mathrm{I}_{\mathrm{UV}}, \mathrm{I}_{\mathrm{G}}$, and $\mathrm{I}_{\mathrm{G}} / \mathrm{I}_{\mathrm{UV}}$ ratio of the $\mathrm{ZnO}$ nanoflower arrays decreased with the thicknesses of the $\mathrm{Al}$ sacrificial layer.

Author Contributions: Conceptualization, H.-W.T., F.-H.W. and C.-F.Y.; methodology, H.-W.T., C.S.W., F.-H.W., H.-W.L. and C.-F.Y.; validation, H.-W.T., C.-S.W., F.-H.W. and C.-F.Y.; formal analysis, H.-W.T., F.-H.W. and C.-F.Y.; investigation, H.-W.T., C.-S.W., F.-H.W. and C.-F.Y.; data curation, H.W.T., C.-S.W. and F.-H.W.; writing-original draft preparation, H.-W.T., F.-H.W. and C.-F.Y.; writingreview and editing, H.-W.T., F.-H.W. and C.-F.Y. All authors have read and agreed to the published version of the manuscript.

Funding: This work was supported by project grants MOST 109-2221-E-390-023, MOST 110-2622-E390-002, and MOST 110-2221-E-390-020.

Data Availability Statement: Not applicable.

Conflicts of Interest: The authors declare no conflict of interest.

\section{References}

1. Rosenberg, M.; Visnapuu, M.; Vija, H.; Kisand, V.; Kasemets, K.; Kahru, A.; Ivask, A. Selective antibiofilm properties and biocompatibility of nano-ZnO and nano-ZnO/Ag coated surfaces. Sci. Rep. 2020, 10, 13478. [CrossRef] [PubMed]

2. Fan, Y.; Xu, Y.; Wang, Y.; Sun, Y. Fabrication and characterization of co-doped ZnO nanodiscs for selective TEA sensor applications with high response, high selectivity and ppb-level detection limit. J. Alloys Compd. 2021, 876, 160170. [CrossRef]

3. Wahyuono, R.A.; Schmidt, C.; Dellith, A.; Dellith, J.; Schulz, M.; Seyring, M.; Rettenmayr, M.; Plentz, J.; Dietzek, B. ZnO nanoflowers-based photoanodes: Aqueous chemical synthesis, microstructure and optical properties. Open Chem. 2016, 14, 158-169. [CrossRef]

4. Wang, C.S.; Wang, F.H.; Liu, H.W. Growth of ZnO nanoflower arrays on a patterned sapphire substrate. Appl. Funct. Mater. 2021, 1,54-59.

5. Baxter, J.B.; Schmuttenmaer, C.A. Conductivity of $\mathrm{ZnO}$ nanowires, nanoparticles, and thin films using time-resolved terahertz spectroscopy. J. Phys. Chem. B. 2006, 110, 25229-25239. [CrossRef]

6. Bhatia, D.; Sharma, H.; Meena, R.S.; Palkar, V.R. A novel ZnO piezoelectric microcantilever energy scavenger: Fabrication and characterization. Sens. Biosensing Res. 2016, 9, 45-52. [CrossRef]

7. Xu, Y.; Jin, J.; Li, X.; Han, Y.; Meng, H.; Wang, T.; Zhang, X. Simple synthesis of ZnO nanoflowers and its photocatalytic performances toward the photodegradation of metamitron. Mater. Res. Bull. 2016, 76, 235-239. [CrossRef]

8. Das, A.; Hazarikaand, M.; Nair, R.G. Synthesis and characterization of ZnO nanoflowers as an efficient solar photocatalyst. AIP Conf. Proc. 2019, 2100, 020096.

9. Zhang, Q.; Dandeneau, C.S.; Zhou, X.; Cao, G. Nanostructures for Dye-Sensitized Solar Cells. Adv. Mater. 2009, 21, 4087-4108. [CrossRef]

10. Jiang, C.Y.; Sun, X.W.; Lo, G.Q.; Kwong, D.L.; Wang, J.X. Improved dye-sensitized solar cells with a ZnO-nanoflower photoanode. Appl. Phys. Lett. 2007, 90, 263501. [CrossRef]

11. Lai, F.I.; Yang, J.F.; Hsu, Y.C.; Kuo, S.Y. Omnidirectional light harvesting enhancement of dye-sensitized solar cells decorated with two-dimensional ZnO nanoflowers. J. Alloys Compd. 2020, 815, 152287. [CrossRef] 
12. Yu, N.; Dong, B.; Yu, W.W.; Hu, B.; Zhang, Y.Q.; Cong, Y. Investigations of ZnO nanostructures grown on patterned sapphire using different precursors in aqueous solutions. Appl. Sur. Sci. 2012, 258, 5729-5732. [CrossRef]

13. Guo, X.; Zhao, Q.; Li, R.; Pan, H.; Guo, X.; Yin, A.; Dai, W. Synthesis of ZnO nanoflowers and their wettabilities and photocatalytic properties. Opt. Express 2010, 18, 18401-18406. [CrossRef] [PubMed]

14. Kim, J.W.; Porte, Y.; Ko, K.Y.; Kim, H.; Myoung, J.M. Micropatternable double-faced ZnO nanoflowers for flexible gas sensor. ACS Appl. Mater. Interfaces 2017, 9, 32876-32886. [CrossRef]

15. Bourfaa, F.; Boutelala, A.; Aida, M.S.; Attaf, N.; Ocak, Y.S. Influence of seed layer surface position on morphology and photocatalysis efficiency of $\mathrm{ZnO}$ nanorods and nanoflowers. J. Nanomater. 2020, 2020, 4072351. [CrossRef]

16. Wei, Y.F.; Chung, W.Y.; Yang, C.F.; Shen, J.R.; Chen, C.C. Using different ions in hydrothermal method to enhance the photoluminescence properties of synthesis ZnO-based nanowires. Electronics 2019, 8, 446. [CrossRef]

17. Singha, J.; Juneja, S.; Palsaniya, S.; Manna, A.K.; Sonia, R.K.; Bhattacharya, J. Evidence of oxygen defects mediated enhanced photocatalytic and antibacterial performance of ZnO nanorods. Colloids Surf. B Biointerfaces 2019, 184, 110541. [CrossRef]

18. Singh, J.; Kumar, S.; Rishikesh; Manna, A.K.; Soni, R.K. Fabrication of $\mathrm{ZnO}-\mathrm{TiO}_{2}$ nanohybrids for rapid sunlight driven photodegradation of textile dyes and antibiotic residue molecules. Optic. Mater. 2020, 107, 110138. [CrossRef]

19. Katiyar, A.; Kumar, N.; Shukla, R.K.; Srivastava, A. Substrate free ultrasonic-assisted hydrothermal growth of ZnO nanoflowers at low temperature. SN Appl. Sci. 2020, 2, 1386. [CrossRef]

20. Huo, D.; Chen, B.; Li, M.; Meng, G.; Le, Y.; Zhu, C. Template-assisted fabrication of Agnanoparticles@ ZnO-nanorods array as recyclable 3D surface enhanced Raman scattering substrate for rapid detection of trace pesticides. Nanotechnology 2021, $32,145302$. [CrossRef]

21. Zhang, J.; Que, W. Preparation and characterization of sol-gel Al-doped ZnO thin films and ZnO nanowire arrays grown on Al-doped ZnO seed layer by hydrothermal method. Sol. Energy Mater Sol. Cells 2010, 94, 2181-2186. [CrossRef]

22. Lin, B.; Fu, Z.; Jia, Y.; Liao, G. Defect photoluminescence of undoping ZnO films and its dependence on annealing conditions. J. Electrochem. Soc. 2001, 148, G110-G113. [CrossRef]

23. Lin, J.H.; Patil, R.A.; Devan, R.S.; Liu, Z.A.; Wang, Y.P.; Ho, C.H.; Liou, Y.; Ma, Y.R. Photoluminescence mechanisms of metallic $\mathrm{Zn}$ nanospheres, semiconducting $\mathrm{ZnO}$ nanoballoons, and metal-semiconductor $\mathrm{Zn} / \mathrm{ZnO}$ nanospheres. Sci. Repo. 2014, 4, 6967. [CrossRef] [PubMed]

24. Vanheusden, K.; Seager, C.H.; Warren, W.L.; Tallant, D.R.; Voigt, J.A. Correlation between photoluminescence and oxygen vacancies in ZnO phosphors. Appl. Phys. Lett. 1996, 68, 403. [CrossRef]

25. Galdámez-Martinez, A.; Santana, G.; Güell, F.; Martínez-Alanis, P.R.; Dutt, A. Photoluminescence of ZnO Nanowires: A review. Nanomaterials 2020, 10, 857. [CrossRef]

26. Jangir, L.K.; Kumari, Y.; Kumar, A.; Kumara, M.; Awasth, K. Investigation of luminescence and structural properties of ZnO nanoparticles, synthesized with different precursors. Mater. Chem. Front. 2017, 1, 1413-1421. [CrossRef]

27. Lin, C.L.; Wang, F.H.; Jhuang, H.S.; Yang, C.F. Effects of different annealing temperatures on the physical, optical, and electrical characteristics and chemical bonds of Ga and F co-doped ZnO films. J. Mater. Res. Technol. 2020, 9, 6331-6342. [CrossRef]

28. Zha, R.; Nadimicherla, R.; Guo, X. Ultraviolet photocatalytic degradation of methyl orange by nanostructured TiO2/ZnO heterojunctions. J. Mater. Chem. A 2015, 3, 6565-6574. [CrossRef] 